\title{
The Feasibility of a Home Telenutrition Intervention for Weight Reduction in Men in West Virginia
}

\author{
Michelle Campion
}

Follow this and additional works at: https://researchrepository.wvu.edu/etd

\section{Recommended Citation}

Campion, Michelle, "The Feasibility of a Home Telenutrition Intervention for Weight Reduction in Men in West Virginia" (2016). Graduate Theses, Dissertations, and Problem Reports. 5305.

https://researchrepository.wvu.edu/etd/5305

This Thesis is protected by copyright and/or related rights. It has been brought to you by the The Research Repository @ WVU with permission from the rights-holder(s). You are free to use this Thesis in any way that is permitted by the copyright and related rights legislation that applies to your use. For other uses you must obtain permission from the rights-holder(s) directly, unless additional rights are indicated by a Creative Commons license in the record and/ or on the work itself. This Thesis has been accepted for inclusion in WVU Graduate Theses, Dissertations, and Problem Reports collection by an authorized administrator of The Research Repository @ WVU. For more information, please contact researchrepository@mail.wvu.edu. 


\title{
The Feasibility of a Home Telenutrition Intervention for \\ Weight Reduction in Men in West Virginia
}

\author{
Michelle Campion
}

Thesis submitted to the Davis College of Agriculture, Natural Resources, and Design at West Virginia University

in partial fulfillment of the requirements for the degree of

Master of Science

in Nutrition and Food Science

\author{
Melissa Ventura-Marra, Ph.D, RD, Chair \\ Robert Taylor, Jr., Ph.D \\ Dina Jones, Ph.D, PT
}

Department of Animal and Nutritional Sciences

Morgantown, West Virginia

2016

Key words: telenutrition, videoconferencing, home-based, men, feasibility

Copyright 2016 Michelle Campion 


\author{
ABSTRACT \\ The Feasibility of a Home Telenutrition Intervention for \\ Weight Reduction in Men in West Virginia \\ Michelle Campion
}

\title{
Background
}

West Virginia (WV) has one of the highest national rates of obesity, especially among middleaged men, and one of the lowest Registered Dietitian Nutritionist (RDN) ratios per capita. Providing nutrition advice via teleconferencing may allow obese WV middle-aged men to overcome access barriers that are preventing them from overcoming obesity. However, before large-scale interventions can be effectively conducted, the feasibility must be assessed.

\section{Objective}

The purpose of this study is to evaluate the feasibility of a home telenutrition weight-loss program using videoconferencing among obese men in WV. Feasibility is assessed through technical difficulties tracked throughout the intervention and through a post-intervention satisfaction survey.

\section{Methods}

A survey was developed to assess the participants' level of satisfaction related to the technological and nutritional care aspects of the intervention. Twenty-seven men aged 40-70 who participated in a 12-week telenutrition weight loss intervention took this survey upon completion of the intervention. The amount and type of technical difficulties were also documented throughout the intervention.

\section{Results}

Eighty-one video calls were attempted throughout the intervention with all but one participant experiencing at least one minor or major technical difficulty either logging on or during the calls. Even with these technical difficulties, overall satisfaction with this mode of delivery was high, regardless of age, income level, education level, employment status, and technical difficulties logging on or during video calls. Previous videoconferencing experience was significantly related to higher satisfaction levels.

\section{Conclusion and summary}

Videoconferencing is a technologically feasible and highly acceptable method of nutrition counseling for the middle-aged, obese male population in WV, as shown with no significant differences between group demographics. Videoconferencing should be used to develop a largerscale intervention for this population to combat obesity within this demographic. 


\section{ACKNOWLEDGEMENTS}

First I would like to thank my committee chair, Dr. Melissa Marra, for providing me with this opportunity to learn and grow and for providing encouragement along the way. I would also like to thank the other members of my thesis committee, Dr. Dina Jones and Dr. Robert Taylor, for the support they provided. I truly appreciate the time from each of you dedicated to helping me complete this task. I would also like to thank Dr. Marra's graduate research assistants, Stephanie Thompson and Paige Starrett and undergraduate students, Maggie Drazba and Alexis Kapostasy, for all their help with the in-person measurement sessions and for entering all of the diet records into the computer. I really appreciate everything you have done; the help and friendship you have given me has been invaluable.

I would also like to thank the MDTV staff, especially Donovan Monday, for being so patient with me and guiding me through each step of correcting the technical difficulties with the video software, no matter what time of day or evening it was. Thank you also to Dr. Christa Lilly for always being patient with me and helping with my many statistics questions. I would like to thank all of the participants who I came to know and appreciate more as the weeks went by. The patience shown through technological difficulties and the motivation to eat healthier and lose weight, especially in moments of struggle with birthday cakes and holiday celebrations, was an inspiration for me. This work truly could not have been possible without all of you.

Finally, I would like to thank my wonderful support system: my husband, parents, sisters, roommates, and friends. Without your constant love, support, and encouragement, I would not have been able to accomplish any of this. Thank you for supporting me on this journey. Most importantly, I am grateful to God for lighting and guiding each step of the way. 
TABLE OF CONTENTS

CHAPTER

PAGE

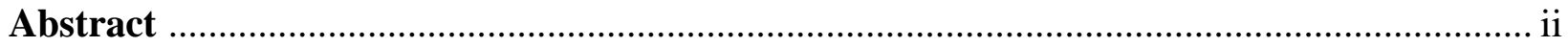

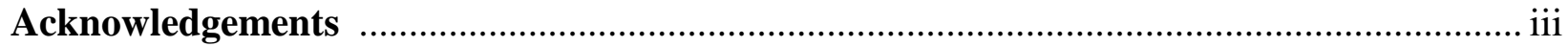

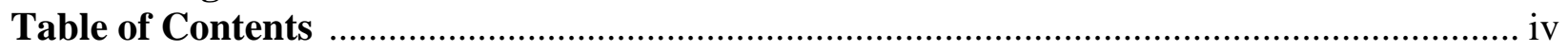

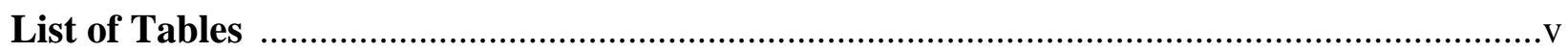

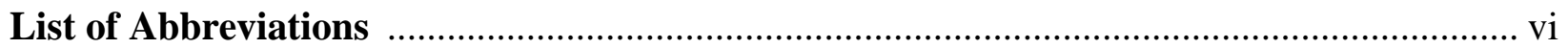

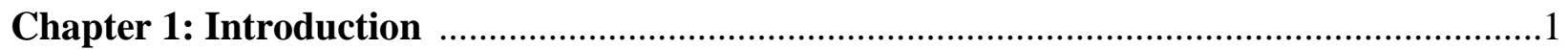

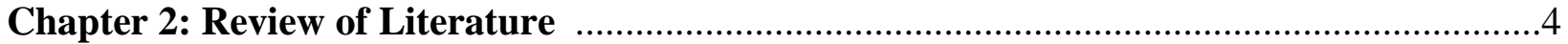

Introduction to Feasibility .................................................................................

Measuring Feasibility: Technical Difficulties ..................................................

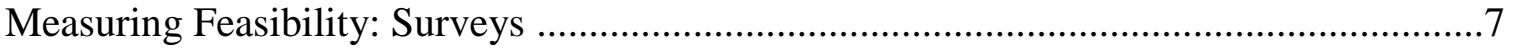

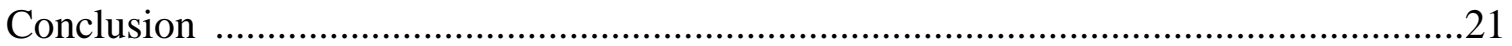

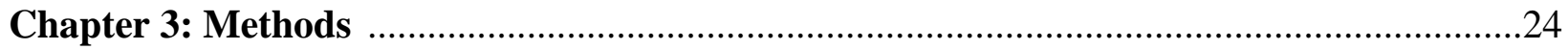

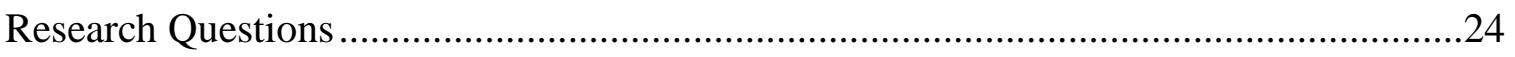

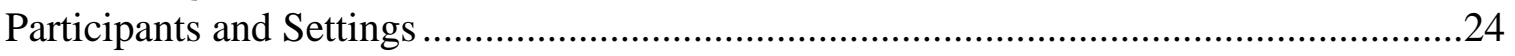

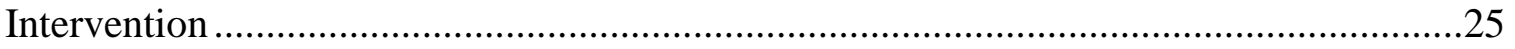

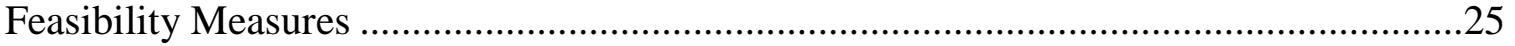

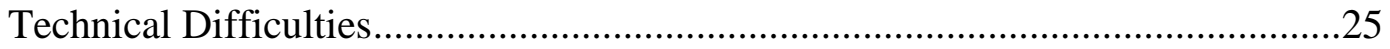

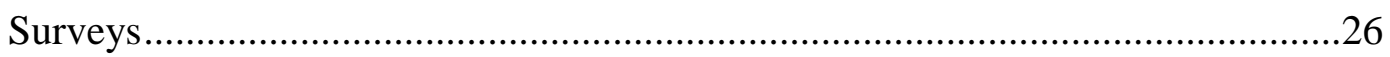

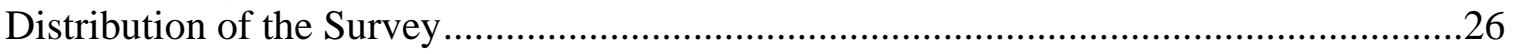

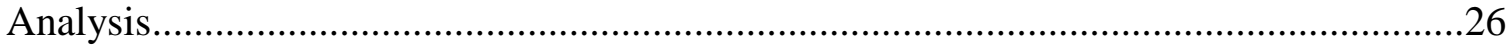

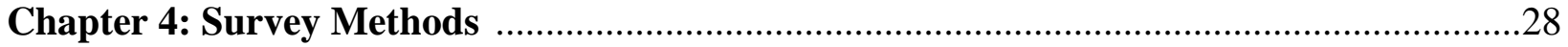

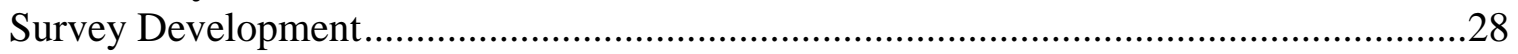

Construct Formation ..........................................................................................28

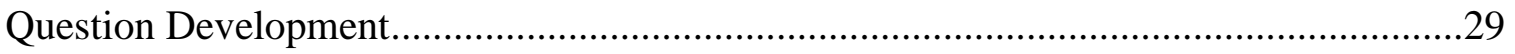

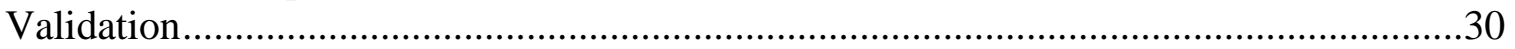

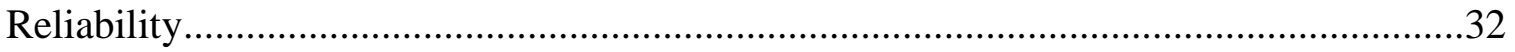

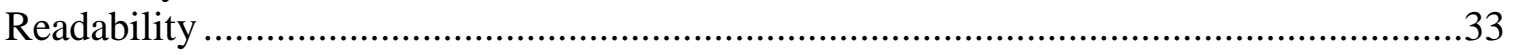

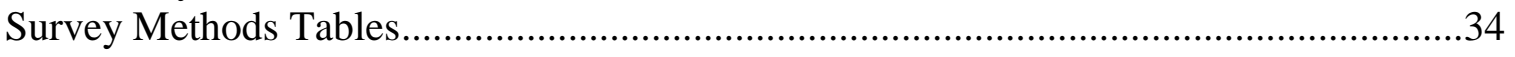

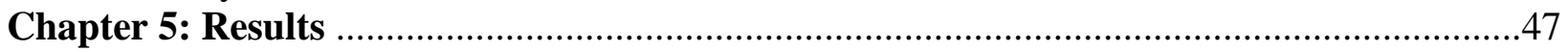

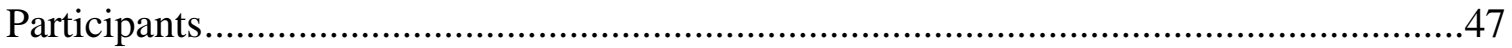

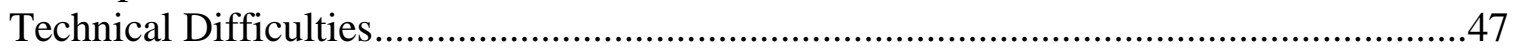

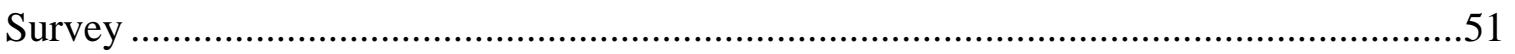

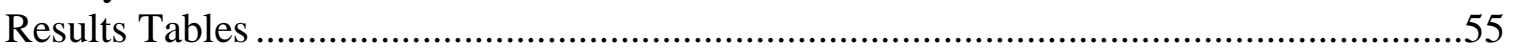

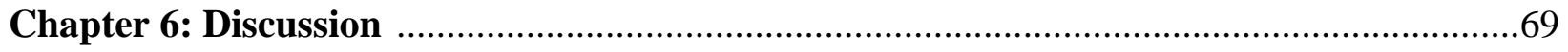

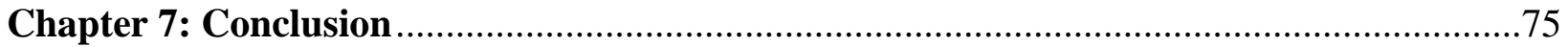

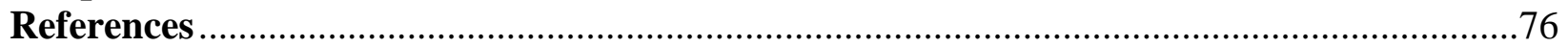




\section{LIST OF TABLES}

Table 1: Satisfaction Survey Technical Aspects: Original Question and Source ...........................34

Table 2: Satisfaction Survey Nutritional Care Aspects: Original Question and Source .................37

Table 3: Satisfaction Survey Technical Aspects: Survey Question and Source ............................41

Table 4: Satisfaction Survey Nutritional Care Aspects: Survey Question and Source ..................42

Table 5: Satisfaction Survey: Definitions of Construct Sub-Scales .............................................43

Table 6: Measurement Scales Used in Surveys From Literature Review ......................................44

Table 7: Final Satisfaction Survey: Readability Level, Construct, and Sub-Scales ......................45

Table 8: Demographics and Mean (SD) of Comparisons on Satisfaction Survey ........................55

Table 9: Technical Issues Faced: Logging into Vidyo Portal ........................................................56

Table 10: Technical Issues Faced: During Video Call ………….............................................57

Table 11: Technical Issues Faced: Type of Issue Logging into Vidyo Portal ................................58

Table 12: Technical Issues Faced: Type of Issue During Video Call.............................................59

Table 13: Satisfaction Survey: Results by Individual Questions ..............................................60

Table 14: Satisfaction Survey: Means and Standard Deviations by Individual Question ..............64

Table 15: Satisfaction Survey: Means and Standard Deviations by Construct .............................66

Table 16: Satisfaction Survey: ANOVA of Comparisons …………….......................................67

Table 17: Satisfaction Survey: T-tests of Comparisons............................................................68 


\section{LIST OF ABBREVIATIONS}

ACC: American College of Cardiology

AHA: American Heart Association

BMI: Body Mass Index

BRFSS: Behavioral Risk Factor Surveillance System

CDC: Centers for Disease Control and Prevention

HIPAA: Health Insurance Portability and Accountability Act

IRB: Institutional Review Board

JMP: John's Macintosh Program

PCP: Primary Care Providers

RDN: Registered Dietitian Nutritionist

TOS: The Obesity Society

USB: Universal Serial Bus

USPSTF: United States Preventative Services Task Force

WV: West Virginia 


\section{CHAPTER 1: INTRODUCTION}

The prevalence of obesity in America continues to grow with an estimated 35 percent of adults now obese, including 36 percent of men. ${ }^{1}$ According to recent state-based data, West Virginia (WV) ranks second highest in obesity prevalence in the nation with more than 35 percent of adults classified as obese, with more men (over thirty-four percent) than women falling into that category in WV. ${ }^{2}$ Nationally, middle-aged adults (45-64 years old) have the highest obesity rates, and midlife adults in WV have the highest percentage of obesity rates in the state at over 40 percent. $^{2}$

Numerous individuals and organizations in the United States are attempting to attack this problem but significant barriers remain to reduce the prevalence of obesity. The American Heart Association (AHA), American College of Cardiology (ACC), and The Obesity Society (TOS) recommend that physicians identify overweight and obese patients and counsel patients in strategies to reduce weight. ${ }^{3}$ Furthermore, the United States Preventative Services Task Force (USPSTF) requires primary care providers (PCPs) to offer behavioral interventions directed towards weight loss to all obese patients or refer them to Registered Dietitian Nutritionists (RDNs). ${ }^{4}$ However, PCPs' inability to devote adequate time in routine visits to conduct nutrition counseling has proven to be a major barrier. ${ }^{5}$ PCPs can refer to RDNs, since they are equipped to provide nutrition counseling, but the limited number of RDNs remains another barrier. With only 17 RDNs per 100,000 residents in $\mathrm{WV}^{6}$ (the second-lowest state in RDN ratio) ${ }^{6}$ PCPs may not know an RDN in their practice area.

One method to overcome this access barrier is through the use of telehealth via videoconferencing. The use of telehealth, which involves using various forms of technology to implement health-based interventions, has been increasing and has provided favorable outcomes 
in regards to weight change and nutritional knowledge. ${ }^{7,8}$ Previous studies have indicated the need for further telehealth research in weight management, especially when the videoconferencing is done in the patients' home ${ }^{9}$ and including face-to-face components. ${ }^{10,11}$ Videoconferencing as a form of telemedicine has demonstrated feasibility in telepsychiatry, ${ }^{12-14}$ teledermatology, ${ }^{15}$ smoking cessation, ${ }^{16}$ and other forms of telemedicine. Recent reviews have reported that internet-based weight loss programs can be as successful as face-to-face programs, ${ }^{17-19}$ demonstrating the need for a more varied and specific population base to test the impact of using the internet in weight loss. ${ }^{17,19}$

Telenutrition, which is the form of telehealth dealing with dietetics, has the ability to increase access to RDNs by delivering long-distance nutrition care using technology. However, before large-scale interventions of telenutrition through videoconferencing can be effectively conducted on midlife adults in WV, the feasibility of this intervention must be assessed.

Feasibility studies serve as the method to design and evaluate whether larger-scale interventions can be implemented and integrated into mainstream practice. ${ }^{20}$

One method of assessing feasibility is by reporting the amount of technical difficulties experienced to compare whether the number of difficulties has a negative impact on satisfaction rates, ${ }^{12}$ as technical issues have been identified as one drawback to telemedicine that negatively affects care. ${ }^{12,21}$ The predominant method by which to assess feasibility includes the use of surveys or questionnaires to measure satisfaction, which have been widely used in telehealth applications. ${ }^{22}$ Surveys are an appropriate means to measure satisfaction because not only are they easily administered and not cumbersome for the respondent,${ }^{23}$ but they also provide valuable information into the perceptions of the individuals to whom the survey is targeted. ${ }^{22,24}$ 
Satisfaction is an important area to be assessed with the use of surveys. Efforts in assessing satisfaction provide valuable information into increasing patient-centered care, ${ }^{23}$ which is a primary approach to helping improve healthcare status. ${ }^{25}$ Furthermore, the degree to which the respondent is satisfied with the specific healthcare intervention impacts its potential future dissemination. ${ }^{26}$ Previous research has indicated some barriers with the use of telemedicine. Some patients prefer face-to-face visits over telemedicine. ${ }^{13,27}$ Additionally the lack of human contact can be a concern. ${ }^{13,15,28}$ Therefore, investigating whether the middle-aged obese male population in WV finds telenutrition to be a satisfactory mode of communication is an important step in determining the feasibility of a videoconferencing intervention for weight loss.

This study will evaluate the feasibility of a culturally targeted home telenutrition weightloss program using videoconferencing among obese men in WV. Feasibility will be assessed through the amount of technical difficulties arising throughout the study and with the use of a questionnaire assessing the satisfaction of the telenutrition program upon completion. 


\section{CHAPTER 2: LITERATURE REVIEW}

\section{Introduction to Feasibility}

Feasibility must be assessed before attempting to make any new process mainstream. ${ }^{20}$ Assessing feasibility is especially important with newer forms of healthcare, such as telehealth, to ensure that the process is able to be implemented on a larger scale. ${ }^{23}$ Telehealth, also known as telemedicine, includes any form of healthcare that is conducted through various forms of electronic means when the healthcare provider and patient are in separate locations. ${ }^{23,29}$ Telenutrition is a form of telehealth that provides an opportunity for more individuals to meet with a Registered Dietitian Nutritionist. ${ }^{30}$ One mode of delivery of telenutrition is through the use of videoconferencing.

Telemedicine feasibility may be assessed using multiple methods. One method to assess feasibility is by reporting the number of technical difficulties experienced to compare whether this number has a negative impact on satisfaction rates, ${ }^{12}$ as technical issues have been identified as one drawback to telemedicine that negatively affects care. ${ }^{12,21}$ The predominant method by which to assess feasibility is through the use of surveys or questionnaires to measure satisfaction, which have been widely used in telehealth applications. ${ }^{22}$

\section{Measuring Feasibility: Technical Difficulties}

The selection of which technical issues to evaluate provides the basis for assessing the feasibility of a telehealth study. In assessing technical issues related to systems in videoconferencing, Clarke and Thiyagarajan ${ }^{21}$ conducted a systematic review to examine which elements needed to be addressed in a technical evaluation. ${ }^{21}$ Using forty-seven articles in the review, nine of the articles dealt with business industry using videoconferencing while the other thirty-eight were related to telehealth. ${ }^{21}$ They found that of these forty-seven articles reviewed, 
twenty-two of the studies used subjective measures to assess the technical evaluation, and over half of these subjective measures (59 percent) used Likert scales and questionnaires to evaluate the technical issues. ${ }^{21}$ (Likert-type questions use an ordered scale that includes both negative and positive perceptions to assess views of responders. ${ }^{31}$ Likert scales have been used extensively across disciplines to quantitatively measure opinions. ${ }^{32}$ ) Areas of focus in the technical area include picture clarity, sound quality, and system functionality. ${ }^{21}$ Technical issues are important to address when reviewing multiple studies in both business and healthcare disciplines for videoconferencing feasibility.

Based on one intervention using videoconferencing with telehealth, Luxton et al. ${ }^{12}$ examined technical issues in an intervention related to psychotherapy. Using telehealth for psychiatry has been proven to be effective in clinical applications, especially those pertaining to military veterans with post-traumatic stress disorder (PTSD). ${ }^{12,33}$ Ten active duty military men ages 21 to 45 participated in a total of seventy-three videoconferencing sessions from their homes. The amount and type of technical issues experienced during the sessions were documented as one assessment measure to evaluate feasibility. ${ }^{12}$ The technical difficulty that occurred most frequently involved problems establishing the videoconferencing connection, which occurred thirty-one times. ${ }^{12}$ However, this problem was typically resolved in less than six minutes. The method used to quickly overcome this barrier was using telephone contact after failed videoconferencing attempts. ${ }^{12}$ No negative effects in the treatment process resulted from this barrier. From this small sample size, the authors concluded that despite technical issues, using videoconferencing was a feasible and satisfactory method of receiving psychotherapy treatment. $^{12}$ 
A study conducted by Parker Oliver et al. ${ }^{34}$ also used videoconferencing to assess if seniors found this mode of delivery to be appropriate for use with healthcare by reviewing the acceptability of technical aspects. Videophones were used to connect twelve seniors, ages 78-89 36 percent of whom were male, living at an assisted living facility with the researchers who were also located at the facility, with each senior making an individual phone call. The researchers noted all technical issues faced by the participants, with difficulties occurring in only two instances. ${ }^{34}$ In one instance, the technology malfunctioned; for the other, the connection was dropped, but the senior was able to successfully reconnect with the researcher. ${ }^{34}$ While a small sample size, the minimal problems faced by this study group of senior citizens demonstrated the feasibility of video calls for seniors.

Davis et al. ${ }^{35}$ also considered technical difficulties in assessing the feasibility of videoconferencing for pediatric weight loss. Their study was conducted with overweight and obese children receiving treatment in a group-based format. ${ }^{35}$ Seventeen mother-child pairs were enrolled and randomized to either the telehealth group or physician visit group, with the telehealth group receiving treatment via videoconferencing. They noted the number of times technical difficulties caused interruption during the sessions, and took into consideration notes and comments from the provider of the telehealth sessions. ${ }^{35}$ Provider notes indicated positive comments on convenience with being able to reach more people at a distance without leaving their healthcare facility. ${ }^{35}$ Participants reported slight delays with the video, but none were significant enough to disrupt the session. They concluded that group-based videoconferencing with overweight and obese children was a technologically feasible method by which to deliver behavioral interventions. ${ }^{35}$ 
As shown in this review of the studies regarding technological aspects of a videoconferencing intervention, counting the number of technical issues occurring in telenutrition sessions provides an important quantitative method of assessing feasibility in a telenutrition study. ${ }^{12,21,34,35}$ Noting the type of problem encountered is also essential to analyze the root cause of the problem and to provide a recommendation to prevent the malfunction from occurring in the future. ${ }^{12,34}$ These methods of accounting for the scope of technical difficulties provide an important basis for the predominant form of assessing telehealth feasibility, surveys by participants that detail their perceptions of the technological aspects of the studies. ${ }^{21,34}$

\section{Measuring Feasibility: Surveys}

\section{A. Pediatrics}

Surveys and questionnaires provide an essential element in measuring feasibility, especially by measuring the satisfaction of the users. ${ }^{22}$ Dick et al. conducted a study using telehealth consultations in multiple pediatric disciplines in which they used videoconferencing as a method to reach patients located in a distant location. ${ }^{36}$ Videoconferencing seemed to be a convenient way for doctors located in Toronto, Canada, to reach patients who were located 840 miles away. ${ }^{36}$

A thirteen-item questionnaire with Likert-style questions related to comfort and satisfaction of videoconferencing was developed. ${ }^{36}$ Questions were related to comfort, technology, and satisfaction. This survey was administered to the family and patient immediately following the consultation, but no specific directions as to who should complete it were provided. This survey was tested to assess whether the questions were clear before it was sent to the patients but was not validated prior to use. Questionnaires were returned from 104 of the 140 sent out (74.3 percent response rate). ${ }^{36}$ Results of the survey showed high levels of overall 
satisfaction with 71 percent of the respondents selecting the highest response relating to

"complete satisfaction," 36 demonstrating the feasibility of telehealth via videoconferencing in the pediatric population.

In another study that tested the pediatric population, the aforementioned study by Davis et al. regarding pediatric weight loss involving overweight and obese children and their parents, these researchers used a post-session survey to assess the feasibility measure of satisfaction. The mothers were asked for their satisfaction with the group-based videoconferencing intervention with two 10-point Likert scale questions and one yes or no question. Based on the results of the Likert-style questions, both overall satisfaction and satisfaction with the intervention elements were very high, a result confirmed by the 100 percent attendance rate. ${ }^{35}$ Mothers taking the survey cited location convenience as a critical attribute for satisfaction - having sessions at the school alleviated the burden on parents, since parents were frequently at the school already - and rural participants did not need to travel to another city. ${ }^{35}$ In addition to being a technologically feasible intervention, this survey confirms that using group-based videoconferencing with overweight and obese children is also a parentally satisfactory method by which to deliver behavioral interventions. ${ }^{35}$

\section{B. Diabetes}

To explain the method by which a telehealth survey was developed and validated, Bakken et al. ${ }^{37}$ examined previously developed telehealth questionnaires to develop a twenty-six item satisfaction and usefulness questionnaire. ${ }^{37}$ This survey was administered to participants at the conclusion of the Informatics for Diabetes Education and Telemedicine (IDEATel) randomized control trial. The IDEATel project was a telehealth intervention related to diabetes using home glucose monitoring equipment and videoconferencing from the home with a nurse 
case manager. ${ }^{38}$ The questionnaire used Likert-style questions on a five-point scale in both English and Spanish and was written at an eighth grade reading level so that all participants, especially those with lower education and literacy levels, would be able to answer the questions accurately. ${ }^{37}$

To develop the survey, the researchers first compiled fifty-one questions from previous telehealth surveys and then selected and edited the most appropriate ones to use for a telehealth intervention for diabetes. Some of the items with the highest priority to be included were satisfaction with the nurse care manager over video, privacy concerns, usability of telehealth equipment, and the usefulness of the video visits. ${ }^{37}$ Each of these items was also provided a Flesch-Kincaid reading level to assess readability. This metric for determining readability assigns a grade level to the question by taking into consideration the number of syllables per word and number of words per sentence. ${ }^{39}$ Once the list was prioritized and shortened, the questions were edited to be phrased so a higher score always indicated the positive response. A bilingual researcher translated the final list into Spanish to generate both the English and Spanish versions. $^{37}$

The researchers distributed this survey by either mailing the survey or conducting it through an in-person interview, with a 66 percent response rate for participants who received the survey via the mail and an 87 percent response rate for participants arranging an in-person interview. ${ }^{37}$ Results indicated that all participants were satisfied with the intervention and found it to be useful. Urban participants were particularly supportive of the intervention methods in their responses; however, most urban participants conducted their survey by answering questions asked in an in-person interview by a physician unrelated to the study vice through a paper survey. ${ }^{37}$ This method of data collection could have influenced the positive perceptions they 
expressed. ${ }^{37}$ This study demonstrates the need for participants to take a survey without researchers or healthcare providers present.

Also conducting a study related to telehealth and diabetes, Timmerberg et al. ${ }^{40}$ conducted a pilot study that examined the feasibility of using videoconferencing for diabetes management. ${ }^{40}$ In total, complete data from thirteen participants in each group (intervention and control) was collected and analyzed with eight of the participants in each group being male (61.5 percent) and the average age being 65.5 years old. ${ }^{40}$ All participants received an RDN-led group-based nutrition counseling session over videoconferencing, with the intervention participants receiving two individual follow-up visits with the RDN after the group session. Two surveys assessed feasibility. The first survey was administered to all participants immediately following the group videoconferencing session; the second survey was administered to the intervention group participants after their final individual session. ${ }^{40}$

The first survey was taken by all twenty-six completers of the group videoconferencing session, but results were not provided; however, results were presented from the intervention group's second survey. The number of total questions asked in the survey was not available, but four specific questions that assessed intervention group satisfaction with their results were given. Based on a five-point Likert scale, all four questions had mean scores ranging between 4.5 and 4.8, demonstrating high overall satisfaction. ${ }^{40}$ More specifically, participants reported that they felt comfortable with videoconferencing for nutrition counseling, found the method to be a convenient mode of delivery, would participate in a program similar to this again, and would recommend a nutrition program conducted over videoconferencing to others. ${ }^{40}$

Also using a group-based videoconferencing format for diabetes patients, this time dealing with diabetes prevention, Vadheim et al. ${ }^{41}$ used a qualitative evaluation to assess 
participant satisfaction. ${ }^{41}$ This group-based intervention was conducted using the Diabetes Prevention Program with one local group at a hospital in Montana (mean age 53 years old, 69 percent female) and one distance group using videoconferencing at a site 79 miles away (mean age 50 years old, 93 percent female); both groups attended the session simultaneously. ${ }^{41}$ While this study reported weight and diabetes outcome results of participants, it did not quantitatively describe levels of participant satisfaction due to few participants completing the evaluation. However, of the small number of responding participants, the researchers reported that participants expressed no difficulties regarding the mode of delivery and had high satisfaction overall. $^{41}$

Also assessing feasibility of videoconferencing for diabetics, Yip et al. ${ }^{24}$ conducted a study in China involving patients who were diagnosed with type two diabetes. These researchers explained the methods by which they developed, validated, and tested a telemedicine satisfaction questionnaire for the participants. ${ }^{24}$ Sixteen males and twenty-two females between the ages of forty and seventy who had a diagnosis of diabetes and were recent referrals to a health care center participated in this study. ${ }^{24}$ Each participant was required to attend four group-based video sessions over the span of four and a half months at the health care center. The researchers administered a satisfaction questionnaire at the end of the study. ${ }^{24}$

The three main areas of the questionnaire were quality of care provided, similarity to face-to-face encounter, and perception of the interaction. ${ }^{24}$ Results demonstrated positive correlation between the participants' level of satisfaction ascertained from the survey, hemoglobin A1C level, and adherence to the program. The authors suggest that communication between providers and patients was enhanced through the use of telemedicine conducted via videoconferencing. This enhancement in communication appears to have motivated participants 
to comply with the study, and may have improved their level of satisfaction, ${ }^{24}$ giving evidence that this video-based format is feasible for diabetes.

\section{Telepsychiatry}

In addition to examining technical issues that occurred with a home-based videoconferencing intervention for PTSD, Luxton et al. ${ }^{12}$ also assessed participant satisfaction in survey format. The researchers used a previously developed satisfaction questionnaire related to psychotherapy that had already been tested for construct validity and internal consistency to assess participant satisfaction. ${ }^{42}$ This survey included eight items that were rated on a four-point scale. ${ }^{12}$ Of the eight participants who completed the videoconferencing sessions, clinical symptoms associated with PTSD and depression improved and overall satisfaction was favorable. $^{12}$

Also conducting a study on telepsychology via videoconferencing, Richardson et al. ${ }^{14}$ examined participant perceptions on satisfaction in rural areas of Western Australia. They conducted an eleven month intervention with six women and two men between the ages of twenty-seven and fifty-two, who were seen for psychotherapy conducted via videoconferencing. ${ }^{14}$ The average number of sessions per participant was 11.2. Following each session, a satisfaction survey was administered that dealt with three question areas: technology, environmental, and therapy-related. The researchers measured the responses to questions on a four-point Likert scale. ${ }^{14}$ Questions on technical satisfaction included ease of use and level of distraction with technology used, aspects of video and sound quality, and therapy-related questions pertained to rapport with the therapist and degree of usefulness of the session being conducted over video. ${ }^{14}$ 
The researchers found that the satisfaction ratings dealing with video-based therapy increased over time, and the participants gave positive ratings for the therapist and the intervention itself. ${ }^{14}$ The lowest average ratings were scored as a 3 on the 4-point scale, which were related to clarity of the video and session usefulness; the highest ratings were 3.8 out of 4 , which were related to technology ease of use and overall satisfaction. ${ }^{14}$ Participant open-ended comments on the surveys toward the end of the intervention expressed that even though they might have rated certain areas lower in regard to the technical aspects, they still had an overall positive experience. Furthermore, they stated that they would tolerate the minimal technical problems in order to receive therapy via telepsychiatry over video in the future, ${ }^{14}$ further demonstrating the feasibility and satisfaction of telemental health applications conducted with the use of videoconferencing. However, the sample sizes for both of these telemental health interventions reviewed were small, limiting the generalizability of these conclusions.

Callahan et al. ${ }^{13}$ also conducted a study on telemental health, this time comparing mental health and non-mental health services with a larger sample size. ${ }^{13}$ Thirty-four participants were seen for various mental health disorders and fifty-nine were seen for other disciplines, including dermatology and cardiology. ${ }^{13}$ Upon completion of the teleconsultation conducted via videoconferencing with the patient at a network site and the medical consultant at the main hospital, each participant evaluated the experience through a questionnaire using a five-point Likert scale. ${ }^{13}$ The four questions on the survey related to the ability to speak freely, endorsement of telehealth appointments in the future, preference for telemedicine over face-toface consultations, and experience of the provider. ${ }^{13}$

For each of the four questions, participants receiving non-mental health services rated the experience slightly higher, but the difference was not significant, with the average rating in the 
mental health group being 4.6 out of 5, while the non-mental health group averaged 4.7 out of 5. ${ }^{13}$ The researchers expected mental health patients to have much lower scores than the nonmental health group; ${ }^{13}$ thus, this study gives further evidence that patients from a wide variety of backgrounds requiring differing levels of care can benefit from and be satisfied with this type of healthcare, favoring its feasibility.

\section{Teledermatology}

Demiris et al. ${ }^{15}$ conducted a review of teledermatology that analyzed multiple studies to identify which portions of a telehealth intervention need to be included in evaluation of the program. ${ }^{15}$ Five studies related to store-and-forward applications and nine studies that used video were identified. Of these fourteen studies, thirteen studies used self-administered surveys and one used telephone interviews to assess the participants' acceptance of and satisfaction with dermatology using telehealth. ${ }^{15}$ The authors concluded that some of the elements to be included in the evaluation were comparing telehealth to face-to-face, preference for the type of consultation, and privacy concerns. ${ }^{15}$ Including open-ended questions was also suggested to address opinions that could not be captured in a rating scale. However, the sample sizes in the studies ranged from 7 to 321 participants; the definition of "satisfaction" varied; and only two studies explained the validity of the questionnaire, making the results from this review difficult to generalize.

\section{E. Telehealth with cancer}

Haozous et al. ${ }^{43}$ and Doorenbos et al. ${ }^{44}$ both conducted studies related to cancer in rural American Indian and Alaska Native communities. ${ }^{43,44}$ In the study by Haozous et al., these researchers provided educational sessions and case conferences relating to the management of cancer pain to primary care providers in the state of Washington via videoconferencing. ${ }^{43}$ 
Haozous et al. provided these educational sessions and case conferences at rural clinics and hospitals in Washington and Alaska to learn how to more effectively help their rural-living cancer patients manage pain. ${ }^{43}$ The providers who attended the sessions were asked to fill out a survey relating to their satisfaction of this mode of delivery. Fifty-six providers completed the survey, and overall satisfaction with telehealth had a score of 3.35 on a 4-point scale, ${ }^{43}$ signifying feasibility and acceptance of the providers.

Doorenbos et al. also conducted a telehealth study related to cancer, focusing on patient support, involving the use of videoconferencing for cancer survivor support groups. ${ }^{44}$ Twelve support group meetings were held in 25 rural areas of Washington and Alaska with the originating sites located in three urban areas: two in Seattle, Washington and one in Anchorage, Alaska. ${ }^{44}$ Fifty of the patients attending the support groups were approached by the researchers after the fifth meeting and asked to complete a satisfaction survey related to the videoconferencing experience. ${ }^{44}$ Of these 50, 32 returned the survey, a 64 percent response rate. ${ }^{44}$ All participants in the support groups were female, and the average age of the survivors who completed the survey was 53 years old. ${ }^{44}$ The satisfaction survey was rated on a five-point Likert scale for six questions, with two additional open-ended questions. The average overall satisfaction with the telehealth was rated 4.59 out of $5,{ }^{44}$ giving further evidence that using videoconferencing for cancer-related diagnoses is a feasible and satisfactory mode of delivery.

\section{F. Breastfeeding}

Friesen et al. ${ }^{45}$ conducted a feasibility study with thirty-five low-income women receiving support on how to breastfeed through videoconferencing. ${ }^{45}$ The majority of the women were between the ages of 20 and 34 years old. The new mothers participated from private rooms in their local community health center and the lactation consultants were in a private room at the 
breastfeeding center. Through the use of interviews after the project was completed, they concluded that receiving breastfeeding support was an easily executed, far-reaching mode of delivery of healthcare. ${ }^{45}$ Furthermore, the recipients might not have been able to receive this breastfeeding support if not for the videoconferencing due to the inconvenient nature of and cost associated with traveling to the breastfeeding center. ${ }^{45}$

As intriguing as certain aspects of this study may be, certain methodological weaknesses limit the ability to draw significant conclusions from the study. The methodology for this study notes that interviews were conducted with "key participants," but the definition of this term is not specified. ${ }^{45}$ Furthermore, only the providers were quoted in the results of the feasibility assessment. In these feasibility results, the providers gave opinions from the mothers, but the direct opinions of the mothers were not included ${ }^{45}$ Even with these methodological weaknesses, the study on telehealth in breastfeeding by Friesen et al. provides compelling evidence of the utility of this method. Further research is needed to deepen the literature on this subset of telemedicine.

\section{G. Telemonitors}

Parks and $\mathrm{Kim}^{46}$ used a larger sample size $(\mathrm{N}=69)$ for a feasibility study related to diabetic insulin pump training. They examined whether this training would be as effective and satisfactory when conducted through videoconferencing to the participants' home as when

conducted via face-to-face training. ${ }^{46}$ The participants chose which method they preferred to be trained in using an insulin pump. The mean age for the group who chose the remote method in the home was 39.7 years old (range 18-60 years old), while the mean age who chose the face-toface method was slightly higher at 41.9 years old (range 18-69 years old). Breakdown by gender was not reported. A twenty-seven item questionnaire was emailed to participants that included 
questions related to participant characteristics, type and reason for training method chosen, ability and confidence using the insulin pump, and satisfaction. Four questions related to satisfaction with the videoconferencing were taken from a previously developed telehealth survey and used a five-point Likert scale. ${ }^{23}$

Thirty-eight surveys were returned, but one was incomplete and thus, excluded. Of the 37 analyzed surveys, 20 were from participants who used the face-to-face method and 17 were from participants who received the training through videoconferencing. ${ }^{46}$ No statistically significant differences between groups were found in competence using the pump and satisfaction level with the chosen training method. Conducting the training through videoconferencing had high overall scores in regards to ability to use the pump, confidence in using the pump, and satisfaction with the pump and training method. The researchers concluded that using videoconferencing as a training method for insulin pumps was as effective and satisfactory as face-to-face training. ${ }^{46}$

\section{H. Smoking cessation}

Carlson et al. ${ }^{16}$ conducted a group-based feasibility study of telehealth for a smoking cessation program. Their study was conducted in Alberta, Canada involving a total of 554 smokers. Three hundred seventy smokers attended in-person sessions in Calgary, while 184 smokers attended the distance sessions which were held via videoconferencing in 16 different local health centers around the province. ${ }^{16}$ The range of ages of the participants was between 20 and 79 years old, with an average of 47; over two-thirds of participants were female (68 percent). ${ }^{16}$ The participants were asked to complete a questionnaire evaluating the telehealth portion of the program at specified times within the last four sessions. This time frame was used so the opinions of a wider population could be reached, rather than collecting solely the views of completers who may be more inclined to be satisfied due to successful completion. ${ }^{16}$ 
Attitudes of in-person and telehealth participants indicate greater support for the efficacy of using telehealth to support smoking cessation, while also providing recommendations to improve the processes of future studies. Of the 370 participants in the in-person group, 65 completed the four questions related to their perceptions of the telehealth program. Questions were related to feelings about the videoconferencing interfering with their groups' learning and potential future interest in using telehealth. Of the 183 participants in the videoconferencing group, 51 completed the thirteen question evaluation which asked questions relating to comfort level, acceptability of the technology for healthcare use, ability to see and hear clearly, privacy concerns, and accessibility and cost to other programs similar to this one. ${ }^{16}$

Through this program evaluation, 64 percent of participants in the in-person group who completed the survey expressed interest in future participation in telehealth, but 37 percent expressed concern that those using telehealth were not as much a part of the group as the inperson. ${ }^{16}$ However, the telehealth participants were overall very satisfied with the program with over 85 percent reporting that videoconferencing was a suitable method of receiving healthcare and 84 reporting being satisfied with the quality of the program. ${ }^{16}$ Over half of the videoconferencing participants also reported that they would not have otherwise been able to attend the program due to high cost associated with travel to the in-person sessions in Calgary; more than 90 percent would have had to travel over 500 kilometers to attend. ${ }^{16}$ They concluded that group-based smoking cessation classes conducted via videoconferencing were a feasible and satisfactory method by which to attend this class, a class the long-distance participants might not have been able to attend otherwise; however, they expressed that the in-person and distance groups should not be held simultaneously. ${ }^{16}$

\section{Parenteral Nutrition}


A study conducted by Saqui et al. ${ }^{47}$ examined the satisfaction of a videoconferencing program for home parenteral nutrition follow-ups in rural areas of Ontario, Canada. ${ }^{47}$

Participants were referred to the telehealth program due to inability to travel to the main hospital in Toronto for follow-ups. An 18 question Likert-style survey was developed and mailed to the participants with questions based off patient-centered standards of the healthcare group providing the telehealth. ${ }^{47}$ Of the 13 surveys mailed, 11 were returned. The average age of the 13 participants mailed the survey was 54.5 years old (range 24-75); no data based on the age of the participants who returned the survey was provided. Four of the thirteen participants were male (30 percent). Patients and their families completed the surveys which showed overall satisfaction with videoconferencing. Some comments from the respondents that contributed to their satisfaction included the ability to see and hear clearly, a high comfort level communicating over video, and improvement of access to care otherwise unavailable. ${ }^{47}$

However, even with a high response rate of surveys sent, the inability to accurately evaluate the entire sample size limits the ability to draw significant conclusions from these responses. Of the 26 participants who lived in rural areas, where the use of telehealth should theoretically be most beneficial, five did not have access to the technology necessary to conduct the videoconferencing, five died during the study, and three were not receiving parenteral nutrition anymore, leaving the thirteen who were mailed the survey. ${ }^{47}$ Further analysis is needed in this subset of telehealth.

\section{J. Geriatrics and hospice}

The study by Parker Oliver et al. ${ }^{34}$ that assessed technological aspects of videoconferencing with seniors also examined the feasibility through the use of a questionnaire completed post-videophone call. Questions were asked on a five-point Likert scale ranging from 
strongly agree to strongly disagree and were related to ease of use, sound quality, video quality, and comfort level with using the technology. ${ }^{34}$ Eleven of the twelve asked to participate completed the questionnaire. Results of the questionnaire indicated that almost three-quarters (71 percent) of the participants found the technology easy to use, and all but one participant either agreed or strongly agreed that he or she felt comfortable using the equipment. ${ }^{34}$ However, one observation that frustrated geriatric participants was that it was difficult for those with hearing aids and those who read lips. Aside from this one complaint, the seniors found the technology appropriate and were interested in future use, ${ }^{34}$ demonstrating that video for healthcare is also feasible in this population.

\section{K. Home health services}

Chae et al. ${ }^{48}$ examined satisfaction of twelve elderly patients who used videoconferencing for home health services. Equal numbers of males and females participated, with a total of five living in a nursing home and seven in their own homes; the mean age was 67.5 years old. ${ }^{48} \mathrm{~A}$ home health care nurse was with the patient during the sessions. Upon completion of the health care visit, the participants were asked to complete a satisfaction survey that was rated with a five-point scale. ${ }^{48}$ The researchers asked questions related to the type of home health service used, characteristics of the home health system used, clinic visit changes, and satisfaction. ${ }^{48}$ Results of the survey indicated that using the telehealth home care decreased significantly the number of visits made to the clinic each month by 34 percent $(p<0.05)$, and that participants were overall satisfied with the service provided, including the video features. ${ }^{48}$ The only significant difference in satisfaction levels with the telecare was related to the location of the patient, with the patients at home being more satisfied than those who were in nursing homes $(p<0.05) .{ }^{48}$ 
Using video-based telehealth in the patients' own home was proven to be a highly satisfactory and feasible mode of delivery.

In another study in home health examining user satisfaction with home telecare equipment, Agrell et al. ${ }^{49}$ interviewed patients who had been receiving care through telehealth to assess their perceptions of feasibility ${ }^{49}$ Various healthcare disciplines that used the home telecare were assessed, including heart diseases, vascular diseases, diabetes, depression, and hypertension. ${ }^{49}$ The researchers were unable to find any previously used well-designed surveys suitable for the research purposes and thus used their own interview questions to gather patients' opinions after receiving a home telecare service. ${ }^{49}$ Thirty-four questions were included in the interview with 31 of them having a two or three scaled response options, and the other three questions being open-ended. ${ }^{49}$

The questions assessed six main content areas, including overall impressions, technological factors, disease management factors, video impressions, physical presence factors, and privacy factors. ${ }^{49}$ Based on the responses of the 15 patients who agreed to be interviewed, all but one patient felt either skeptical or neutral about home telehealth prior to using it, but by the end, the participants indicated a transformation in opinion, with the vast majority (93 percent) expressing willingness to use it in the future. ${ }^{49}$ The results of this study demonstrate the satisfaction and feasibility of this type of telehealth use in the home.

\section{Conclusion}

A variety of methods can be used to evaluate telehealth interventions both in terms of patient satisfaction and clinical marker improvement. Based on review of the literature, questionnaires are the most frequently used and seemingly simple form of evaluating telehealth

interventions, especially when using a survey to assess satisfaction. ${ }^{24}$ Telehealth surveys have 
been used in pediatrics, ${ }^{35,36}$ diabetes, ${ }^{24,37,40,41}$ mental health, ${ }^{12-14}$ dermatology, ${ }^{15}$ cancer, ${ }^{43,44}$ breastfeeding ${ }^{45}$ diabetic insulin pump training ${ }^{46}$ smoking cessation, ${ }^{16}$ parenteral nutrition, ${ }^{47}$ geriatrics ${ }^{34}$ and home health services. ${ }^{48,49}$ The overall satisfaction rates were favorable, ${ }^{12-14,16,43-}$ $46,48,49$ even in the wake of technical difficulties, ${ }^{12}$ which should also be assessed when measuring feasibility. ${ }^{12,21,34,35}$ Reviewing previously used surveys, ${ }^{37}$ assessing the most important facets of telemedicine, ${ }^{15,37}$ producing a survey, ${ }^{22,24,37}$ validating the produced survey,,${ }^{15,37}$ ensuring the directions for who to take the survey are clear, ${ }^{36}$ and healthcare providers or researchers being absent when the participants are taking the survey ${ }^{37}$ all play important roles when determining feasibility.

The literature also demonstrates telehealth's success in improving clinical markers in all health care specialties studied. These clinical improvements were the result of behavior modification, which has implications for weight loss and the comorbidities associated with obesity. With more limited access to specific healthcare domains in rural areas, as evidenced in Alberta ${ }^{16}$ and Ontario, ${ }^{47}$ Canada, Western Australia, ${ }^{14}$ or in rural states such as Montana ${ }^{41}$ and Alaska ${ }^{43,44}$ resembling the lack of access to nutrition-related services in rural areas of WV, this review of studies demonstrates that videoconferencing is a potential solution to these access barriers. Furthermore, conducting studies in a location that is convenient for the participants, for example from their home or at their child's school, has been shown to improve clinical markers and participant satisfaction.

Several lessons learned are taken from the methodological weaknesses of previous feasibility studies. First, the study design should be clear as to who will assess the feasibility for example the provider, participant, participants' families, or a combination of these groups. The results of all responders should also be reported as well as the results of all questions asked, 
not just those questions yielding favorable results. As shown in the studies reviewed, a wide age range has been studied, but analysis of men in the middle-aged group has been minimal. While one study had only men enrolled, ${ }^{12}$ and three studies studied solely women, ${ }^{35,44,45}$ most of the time, a mixture of males and females was observed. In the solely male participant study, the age range was lower with the oldest participant being 45 years old. Therefore, future research on middle-aged men is needed when assessing videoconferencing interventions.

In summary, the literature on telehealth has provided important conclusions on the feasibility of this method for dietary counseling. This initial research confirms that telenutrition can hold an important place among more traditional forms of dietetic advising. This literature also provides thought-provoking analysis that should improve the methods of future work in the field of telenutrition. Greater clarity in research design and expansion of the literature to include other demographics will enhance the literature on this topic. 


\section{CHAPTER 3: METHODS}

\section{Research Questions}

To assess the feasibility of the intervention, the following research questions will be evaluated:

1. Are technical difficulties infrequent enough for our method of telenutrition to be an acceptable mode of delivery as determined by participant reaction to technical difficulties?

2. Is the satisfaction level of participants as assessed through the use of a questionnaire regarding this mode of delivery as a type of nutrition counseling sufficient to recommend increasing the use of our method of telenutrition on a larger scale for this demographic?

\section{Participants and Settings}

The participants for this study included those individuals who were randomly assigned to the intervention group of a telenutrition weight loss pilot study designed for men. No additional compensation was provided for the completion of this particular survey but participants received a \$100 gift card for participating in the larger study. Criteria for inclusion in the larger pilot study included being a 40-70 year old man with a BMI of $\geq 30.0 \mathrm{~kg} / \mathrm{m}^{2}$ living with a spouse or companion and at least one of the following cardiovascular risk factors: pre-diabetes, diabetes, hypertension, or dyslipidemia. Participants were also required to have a telephone and home computer with one free USB port and high-speed internet access. Potential participants were excluded if they had a current diagnosis of cancer, celiac disease, any bacterial or viral infections, renal or liver disease (except non-alcoholic fatty liver disease or steatohepatitis), or any condition that limited the intake of fruits and vegetables; if they had a stroke, heart attack or major surgery in the six months prior to the start of the study; if they had a pacemaker or defibrillator; if they were taking insulin, anti-obesity medications, steroids, or warfarin; if they were already on a diet to lose weight; if they had lost ten pounds or more in the previous six 
months; or if they consumed more than two alcoholic beverages daily. The study was approved by West Virginia University’s Institutional Review Board (IRB) as part of the larger study.

\section{Intervention}

The 12-week intervention on which this study is based was conducted from February through May 2016 and included three videoconferencing sessions delivered by an RDN via a HIPAA-compliant videoconferencing platform (Vidyo, Inc., Hackensack, New Jersey). At the baseline session, participants in the intervention group were given: a webcam (HD Pro Webcam C920, 1080p; Logitech, Silicon Valley, California), an instructional lesson on how to set up and use the videoconferencing software, and a booklet containing weight loss information, a technology instruction sheet, and self-monitoring tools.

The three encounters involving the participant and RDN over videoconferencing were scheduled to be conducted at weeks one, five and nine of the study. However, due to conflicts in participants' schedules, the calls were sometimes held on alternate weeks, but three video calls were attempted with each participant. The quantity and type of technical difficulties faced during the video sessions were recorded by the RDN. During the weeks in which the participants did not hold a videoconference, a participant-led discussion with the RDN occurred over the telephone. At the end of the intervention, participants were asked to complete a survey with questions related to satisfaction levels of the technical and nutritional care aspects of the videoconferencing (detailed below).

\section{Feasibility Measures}

\section{Technical Difficulties}

Throughout the video calls, the RDN recorded the frequency and types of technical difficulties occurring when logging on to the video software to investigate which types of 
difficulties caused the highest number of issues. The RDN also noted the amount of time taken to correct incidents when logging on. When technical difficulties occurred while the video calls were in progress, the RDN recorded the type and amount of problems to see which problems created the greatest barriers. The RDN also noted whether the problem was able to be fixed as well as the method used to overcome the problem.

Survey

A questionnaire was created related to participant satisfaction since no previously-made surveys specific to the purposes of this research were available. The survey was distributed to participants during the final week of the intervention to determine satisfaction in regards to technical aspects, professional-patient interaction, patients' feelings about the consultation, and overall satisfaction. Chapter 4 provides additional details regarding survey development methods. Comparative measures used with the satisfaction survey, such as age, income level, and education level, were ascertained from a demographic survey used at the start of the intervention.

\section{Distribution of the Survey}

Upon completion of the twelve week pilot study, the survey was sent via email through the survey software Research Electronic Data Capture (REDCap), a secure website used for building and managing online surveys. ${ }^{50}$

\section{Analysis}

All analyses were conducted using JMP statistical software (SAS Institute Inc., Cary, NC). ${ }^{51}$ Participant characteristics of categorical variables were described in terms of counts and percentages, while characteristics of continuous variables were described in mean and standard deviation. In analyzing technical issues, descriptive statistics were reported for the number of times problems occurred. 
The satisfaction survey was analyzed by first calculating the number of participants who responded favorably (5) or unfavorably (1) to each item on a five-point Likert-scale. Then the satisfaction scale was described in terms of mean, standard deviation, and upper and lower 95 percent of the mean. For comparisons between groups with mean survey satisfaction scores, ttests or one-way analysis of variance were used, as appropriate, for categorical independent variables. Categories for comparison were grouped based on natural breakdowns of categories or by identifying the median of the sample. The following relationships were examined with survey scores: age range (40-49 years vs. 50-59 years vs. 60-70 years); annual household income level (less than $\$ 75,000$ vs. $\$ 75,000$ or greater); highest grade level of school completed (grade 12 or GED vs. one to three years of college vs. four or more years of college); employment status (currently employed vs. not currently employed); if problems logging into the videoconferencing software were unable to be fixed (yes vs. no); if major technology issues were faced during the videoconferencing sessions (yes vs. no); if the participant had previous videoconferencing experience (strongly disagree vs. disagree vs. neutral vs. agree vs. strongly agree); and if the participant had previous videoconferencing experience (all other categories vs. strongly agree). 


\section{CHAPTER 4: SURVEY METHODS}

\section{Survey Development}

A survey was developed to measure the participants' perceived level of satisfaction with the videoconferencing calls. Satisfaction was evaluated on the ability of the intervention to fulfill the individual's expectations in relation to the nutrition care received. Items included in the survey were selected from multiple sources based on a literature review. An initial literature review was conducted by searching Pubmed and EbscoHost databases using a combination of the following search terms: telehealth, telemedicine, video, videoconferencing, feasibility, and satisfaction. The only sources used were those involving telehealth and measures of satisfaction in which the questions that assessed satisfaction were provided. Additionally, the reference sections of review papers used were searched for additional relevant articles. Some sources used

were telemedicine literature, including information from the American Telemedicine Association and the Institute of Medicine. Previously used telemedicine satisfaction surveys from other disciplines were also reviewed, including tele-mental health surveys, where much of telemedicine research has been conducted, teledermatology, and tele-diabetes care. The questions selected for the survey and their original sources are detailed in Tables 1 and 2 at the end of this chapter.

\section{Construct Formation}

The constructs addressed in the questions were technical aspects, professional-patient interaction, patient's feelings about consultation, and overall satisfaction. The literature on telehealth has demonstrated that these aspects are the most frequently asked questions related to satisfaction. $^{27}$ 
These four constructs were broken down into aspects that defined each construct.

Technical aspects were broken down into comfort/ease of use, sound quality, and picture quality. Professional-patient interaction was broken down into comfort, ability to establish rapport, and patient-provider communication. Patients' feelings about the consultation were broken down into comfort, privacy, convenience, usefulness, frequency, and preference. Overall satisfaction included satisfaction with both technical and nutritional care aspects.

Other aspects of these constructs identified in the literature review, such as anxiety level associated with the use of telemedicine, patient cost of the use of telemedicine, concern about technology support, and discipline-specific questions (i.e., questions related to skin care with teledermatology or psychological aspects with tele-mental health) were excluded due to not being applicable to this particular intervention.

The questions also addressed drawbacks that have been identified previously in telemedicine literature involving videoconferencing, such as technical issues negatively affecting care ${ }^{12,21}$ preference for face-to-face visits, ${ }^{13,27}$ lack of human contact being an issue, ${ }^{13,15,28}$ and privacy of personal medical information being compromised. ${ }^{15,28,49}$ A summary table of the questions based on the related constructs and questions found during the literature review are listed in Tables 3 and 4 at the end of this chapter. A summary table of the constructs and definitions are listed in Table 5.

\section{Question Development}

Statements for the questionnaire were written with simple language; contained concise questions; avoided double-barreled questions; and did not include biased or leading questions. ${ }^{22,52,53}$ Twenty-eight questions relating to participant satisfaction of various aspects of telemedicine were scaled on a five-point Likert-scale ranging from strongly disagree (1) to 
strongly agree (5). Likert scales were used in ten of the fourteen applicable sources used to construct this survey, including 36 percent of articles (34 out of 93 studies) in one review of telemedicine satisfaction studies ${ }^{27}$ and 59 percent of articles (27 out of 47 studies) in a review related to the technical evaluation of telehealth. ${ }^{21}$ Two of the other studies used five-point scales that were not classified as Likert scales, ${ }^{44,48}$ and two others used verbal interviews. ${ }^{28,49}$

The final version of the survey consisted of 24 questions. The number of survey questions should be low enough that answering does not become burdensome for the participants; previous telenutrition satisfaction surveys ranged from one question to thirty-four questions. ${ }^{27}$ Table 6 provides the measurement scale used in the sixteen sources of questions used to create the survey in this study.

\section{Validation}

Several steps were completed to assess the validity of the survey developed. Validation of a survey refers to the process done to ensure that the item that is intended to be measured in a particular question is actually being measured in that question. ${ }^{23,53,54}$ Ensuring validity of a survey is an important step in survey development, ${ }^{15,37}$ but was not conducted in a majority (80 out of 93,86 percent) of telemedicine satisfaction studies identified in a review of the literature ${ }^{27}$ nor in any of the studies ( 0 out of 14,0 percent) of a teledermatology review. ${ }^{15}$

Content validity is the type of validity that determines the degree to which relevant issues effectively address the constructs represented in the survey ${ }^{53}$ Face validity, a type of content validity, refers to the degree to which questions appear to the layperson as measuring the specific construct. ${ }^{53}$ This type of validity is the simplest to assess ${ }^{22}$ and was included in the content validation process. The 24 question survey for this study was sent to a panel of professionals to assess the representativeness, clarity, and relevance related to telenutrition conducted via 
videoconferencing, as outlined as the first step of content validation, ${ }^{53}$ and the method by which face validity is addressed. ${ }^{22}$

Comments the professionals made were taken into account, and the questions were modified based on the suggestions provided. Two of these were simplified to make the question easier to understand, one eliminated a double-negative, and one removed the phrase "a lot of" due to ambiguity in the definition of this phrase, as suggested in the literature. ${ }^{53}$

Twenty-five Likert scale questions and two open-ended questions were included in the final survey. The final set of questions was edited to have a common structure. The first question in this final version was a comparison measure and was not used to measure satisfaction. Of the twenty-four questions used to measure satisfaction, seven questions related to the technical aspects, which were broken down into three questions related to comfort or ease of use, two questions for sound quality, and two questions for picture quality. Eight questions assessed professional-patient interaction, with one question related to comfort, four questions related to the ability to establish rapport, and three questions related to patient-provider communication. Patients' feelings about the consultation included eight questions which were broken down into one question each for comfort, privacy, convenience, and preference, and two questions each for both usefulness and frequency (The question that dealt with comfort was identified with both constructs of professional-patient interaction and patient's feelings about consultation.). Overall satisfaction included one question for satisfaction of technical aspects and one for nutritional care aspects. The score for each of the Likert scale questions for satisfaction ranged from 1 to 5; therefore, a higher score indicates more favorable perceptions. The open-ended questions were included to allow participants to add additional comments relating to their perceptions of the technical and nutritional care aspects of the telenutrition experience. 
In the final set of questions, 19 were phrased positively and five were phrased negatively in an attempt to have the participants read each question in its entirety and thoughtfully consider each one, thus decreasing the halo effect. The halo effect refers to participants' tendency to answer every question the same way while not carefully reading each question, due to an overall positive or negative attitude towards the intervention coupled with a list of questions that all have either a positive or negative phrasing. ${ }^{22}$ Table 7 provides the final set of questions for the survey, including the construct and aspect of each construct being measured by each question.

\section{Reliability}

Reliability of a survey refers to the ability of the results to be reproduced if the same participants were to take the test again. ${ }^{22,53}$ Internal consistency reliability was measured using Cronbach's alpha, which measures the degree of correlation between items on the survey. ${ }^{55}$ The value is between zero and one, with higher scores denoting higher reliability. ${ }^{53} \mathrm{~A}$ value greater than 0.7 demonstrates an acceptable correlation. ${ }^{56}$ For the reliability analysis using Cronbach's alpha, correlations between the 24 survey questions related to satisfaction ranged from $0.9144-$ 0.9259, with the entire set of questions yielding Cronbach's alpha of 0.9217 .

Regarding the seven questions on the survey that dealt with technical aspects of the telenutrition experience, Cronbach's alpha for reliability was 0.8379 . From the eight questions regarding professional-patient interaction, Cronbach's alpha for reliability was 0.8597 . From the eight questions regarding the patient's feelings about the consultation, Cronbach's alpha for reliability was 0.8586 . From the two questions measuring overall satisfaction, Cronbach's alpha for reliability was 0.6413 .

The levels of reliability for the first three constructs demonstrate an acceptable correlation, indicating that this survey could be reliably replicated among the same participants. 
For the final construct dealing with overall satisfaction, the two questions dealt with overall satisfaction with the technology and with the nutrition care aspects. These items may differ due to having issues with the technology but still expressing satisfaction with the nutritional care, thereby decreasing the reliability of the construct.

\section{Readability}

Readability of survey questions selected was assessed using the Flesch-Kincaid Grade Level test. ${ }^{22}$ This readability test takes into account the length of the sentence, the number of words in the sentence, and the number of syllables per word; this test uses these criteria to provide a number that corresponds to a grade level in school. ${ }^{22,39}$ When compared to other readability tests, the Flesch-Kincaid Grade Level has been shown to be most reliable for use with junior high through high school grade levels. ${ }^{57}$ This grade span was the goal readability range for this survey based on prior research of a "low-literacy" survey achieving a level of eighth grade. ${ }^{37}$

The final survey used for this study was enhanced from previous drafts of this survey, by simplifying the vocabulary used in the questions asked. The word "videoconferencing" was changed in eleven questions of the final survey to "video session" or "video calls" for ease of reading. Words that resulted in higher than desired readability levels but were common to participants due to the nature of the study, for example "dietitian" and "technology," were considered acceptable to include in the questions. ${ }^{37}$

Table 7 provides the readability level of each question. The mean readability level of all questions used was 8.7 , with individual questions ranging from 2.4 to 13.8 . 


\begin{tabular}{|c|c|c|}
\hline Our Question & Construct and Source & Original Question and Source \\
\hline Measuring comfort/Ease of Use & & $\begin{array}{l}\text { Measurement: subjective ratings of } \\
\text { comfort (ATA: TMH) }\end{array}$ \\
\hline Technical aspects & Technical aspects (Williams) & \\
\hline $\begin{array}{l}\text { 1. Prior to this program, I had experience } \\
\text { communicating via video calls (like } \\
\text { Facetime or Skype). }\end{array}$ & $\begin{array}{l}\text { Measurement: familiarity (past use). } \\
\text { (ATA: TMH) }\end{array}$ & \\
\hline 2. The webcam was easy to use. & $\begin{array}{l}\text { Measurement: usability of the } \\
\text { technology (ATA: TMH) } \\
\text { Item that needs to be addressed: Use } \\
\text { of equipment (Demiris) } \\
\text { Technology area to be assessed: ease } \\
\text { of use (Clarke) } \\
\text { Comfort with technology } \\
\text { (Richardson) } \\
\text { Perceived ease of use (Rahimpour) }\end{array}$ & $\begin{array}{l}\text { The telemedicine equipment is easy to } \\
\text { use. (Bakken) } \\
\text { Was the technology easy to use? (Parker } \\
\text { Oliver) }\end{array}$ \\
\hline 3. The video call software was easy to use. & $\begin{array}{l}\text { Measurement: usability of the } \\
\text { technology (ATA: TMH) } \\
\text { Item that needs to be addressed: Use } \\
\text { of equipment (Demiris) } \\
\text { Technology area to be assessed: ease } \\
\text { of use (Clarke) } \\
\text { Comfort with technology } \\
\text { (Richardson) } \\
\text { Perceived ease of use (Rahimpour) }\end{array}$ & $\begin{array}{l}\text { The telemedicine equipment is easy to } \\
\text { use. (Bakken) } \\
\text { Was the technology easy to use? (Parker } \\
\text { Oliver) }\end{array}$ \\
\hline $\begin{array}{l}\text { 4. There was good sound quality during the } \\
\text { video sessions. }\end{array}$ & $\begin{array}{l}\text { Technology area to be assessed: video } \\
\text { and sound quality (Clarke) } \\
\text { Sound Clarity (Richardson) } \\
\text { Item: Sound quality (Haozous) } \\
\text { Variable: Sound quality (Doorenbos) }\end{array}$ & $\begin{array}{l}\text { I can hear my health-care provider clearly } \\
\text { (Yip) } \\
\text { Did you have trouble hearing your } \\
\text { specialist during the consultation? (Dick) } \\
\text { Was the sound satisfactory? (Parker } \\
\text { Oliver) }\end{array}$ \\
\hline
\end{tabular}




\begin{tabular}{|c|c|c|}
\hline & $\begin{array}{l}\text { Quality of verbal communication } \\
\text { (Chae) }\end{array}$ & \\
\hline $\begin{array}{l}\text { 5. There was good video quality in the } \\
\text { video sessions. }\end{array}$ & $\begin{array}{l}\text { Technology area to be assessed: video } \\
\text { and sound quality (Clarke) } \\
\text { Picture Clarity (Richardson) } \\
\text { Item: Picture quality (Haozous) } \\
\text { Variable: Picture quality (Doorenbos) } \\
\text { Quality of image (Chae) }\end{array}$ & $\begin{array}{l}\text { I can see my health-care provider as if we } \\
\text { met in person (Yip) } \\
\text { Did you have trouble seeing your } \\
\text { specialist during the consultation? (Dick) } \\
\text { Was the picture quality satisfactory? } \\
\text { (Parker Oliver) }\end{array}$ \\
\hline $\begin{array}{l}\text { 6. I was able to hear the dietitian clearly } \\
\text { during the video sessions. }\end{array}$ & $\begin{array}{l}\text { Technology area to be assessed: video } \\
\text { and sound quality (Clarke) } \\
\text { Sound Clarity (Richardson) } \\
\text { Item: Sound quality (Haozous) } \\
\text { Variable: Sound quality (Doorenbos) } \\
\text { Quality of verbal communication } \\
\text { (Chae) }\end{array}$ & $\begin{array}{l}\text { I can hear my health-care provider clearly } \\
\text { (Yip) } \\
\text { Did you have trouble hearing your } \\
\text { specialist during the consultation? (Dick) } \\
\text { Was the sound satisfactory? (Parker } \\
\text { Oliver) }\end{array}$ \\
\hline $\begin{array}{l}\text { 7. I was able to see the dietitian clearly } \\
\text { during the video sessions. }\end{array}$ & $\begin{array}{l}\text { Technology area to be assessed: video } \\
\text { and sound quality (Clarke) } \\
\text { Picture Clarity (Richardson) } \\
\text { Item: Picture quality (Haozous) } \\
\text { Variable: Picture quality (Doorenbos) } \\
\text { Quality of image (Chae) }\end{array}$ & $\begin{array}{l}\text { I can see my health-care provider as if we } \\
\text { met in person (Yip) } \\
\text { Did you have trouble seeing your } \\
\text { specialist during the consultation? (Dick) } \\
\text { Was the picture quality satisfactory? } \\
\text { (Parker Oliver) }\end{array}$ \\
\hline $\begin{array}{l}\text { 8. I was not able to focus on what the } \\
\text { dietitian was saying because I was } \\
\text { distracted by the technology. }\end{array}$ & $\begin{array}{l}\text { Distraction of technology } \\
\text { (Richardson) }\end{array}$ & \\
\hline $\begin{array}{l}\text { 9. Overall, I was satisfied with the use of } \\
\text { technology as a way to receive nutrition } \\
\text { care. }\end{array}$ & $\begin{array}{l}\text { Overall satisfaction (Richardson) } \\
\text { Measurement: patient satisfaction? } \\
\text { (ATA: TMH) } \\
\text { Item: Overall satisfaction with } \\
\text { telehealth (Haozous) } \\
\text { Variable: Satisfaction with telehealth } \\
\text { (Doorenbos) } \\
\text { Patient satisfaction level (Chae) } \\
\text { Overall satisfaction (Williams) }\end{array}$ & $\begin{array}{l}\text { Patient's subjective satisfaction and } \\
\text { experience with the TMH service } \\
\text { provided. (ATA: TMH) } \\
\text { Overall, how satisfied were patients with } \\
\text { the telemedicine services they received? } \\
\text { (IOM) } \\
\text { In general, I am satisfied with the } \\
\text { telemedicine system. (Bakken) }\end{array}$ \\
\hline
\end{tabular}




\begin{tabular}{|l|l|l|}
\hline & $\begin{array}{l}\text { Overall attitude toward the Home } \\
\text { Telecare Management System } \\
\text { (Rahimpour) }\end{array}$ & $\begin{array}{l}\text { Please rate your overall satisfaction level } \\
\text { with TM. (Dick) } \\
\text { Overall, I am satisfied with the quality of } \\
\text { service being provided via telemedicine. } \\
\text { (Yip) } \\
\text { How satisfied are/were you with home } \\
\text { telecare? (Agrell) }\end{array}$ \\
\hline
\end{tabular}




\begin{tabular}{|c|c|c|}
\hline Our Question & Construct & Original Question and Source \\
\hline $\begin{array}{l}\text { 10. I felt comfortable talking to the dietitian } \\
\text { using video calls. }\end{array}$ & $\begin{array}{l}\text { Measurement: subjective ratings of } \\
\text { comfort (ATA: TMH) } \\
\text { Item: Comfort with asking questions } \\
\text { via telehealth (Haozous) } \\
\text { Variable: Comfort with asking } \\
\text { questions via telehealth (Doorenbos) } \\
\text { Ability to speak freely (Callahan) } \\
\text { Experience (comfort, embarrassment) } \\
\text { (Williams) }\end{array}$ & $\begin{array}{l}\text { How did patients rate their physical and } \\
\text { psychological comfort with the application? } \\
\text { (IOM) } \\
\text { At the end of your consultation, how } \\
\text { comfortable were you with the idea of } \\
\text { speaking to your specialist through TM? } \\
\text { (Dick) } \\
\text { I feel comfortable communicating with my } \\
\text { health-care provider. (Yip) } \\
\text { I am comfortable using the equipment. } \\
\text { (Parker Oliver) }\end{array}$ \\
\hline $\begin{array}{l}\text { 11. Not having direct physical contact with } \\
\text { the dietitian was a problem. }\end{array}$ & $\begin{array}{l}\text { Item that needs to be addressed: Lack } \\
\text { of physical contact (Demiris) } \\
\text { Concerns: Lack of physical presence } \\
\text { of a health care provider } \\
\text { (Rahimpour) }\end{array}$ & $\begin{array}{l}\text { Was the lack of direct physical contact with } \\
\text { the distant clinician acceptable? (IOM) } \\
\text { The lack of physical contact during a video } \\
\text { visit is not a problem. (Bakken) } \\
\text { The lack of direct physical contact with the } \\
\text { nurse with telecare was acceptable. (Agrell) }\end{array}$ \\
\hline $\begin{array}{l}\text { 12. I was concerned about the privacy of my } \\
\text { personal medical information during the } \\
\text { video visits. }\end{array}$ & $\begin{array}{l}\text { Item that needs to be addressed: } \\
\text { Possible concerns about privacy and } \\
\text { confidentiality of medical data } \\
\text { (Demiris) } \\
\text { Concerns: Confidentiality } \\
\text { (Rahimpour) }\end{array}$ & $\begin{array}{l}\text { Did patients have concerns about whether } \\
\text { the privacy of personal medical information } \\
\text { was protected? (IOM) } \\
\text { My privacy is protected during video visits. } \\
\text { (Bakken) } \\
\text { Do you feel that your privacy was } \\
\text { respected during the TM consultation? } \\
\text { (Dick) } \\
\text { I have been concerned about whether the } \\
\text { privacy of my personal medical } \\
\text { information was protected. (Agrell) }\end{array}$ \\
\hline
\end{tabular}




\begin{tabular}{|c|c|c|}
\hline $\begin{array}{l}\text { 13. I would have preferred to meet with the } \\
\text { dietitian in person rather than via video } \\
\text { calls. }\end{array}$ & $\begin{array}{l}\text { Measurement: would patient refer } \\
\text { others to this service? (ATA: TMH) } \\
\text { Relative preference for a } \\
\text { telemedicine visit compared with a } \\
\text { face-to-face visit. (Callahan) } \\
\text { Preferences between tele-medicine } \\
\text { and } \\
\text { face-to-face consultation (Williams) }\end{array}$ & \\
\hline $\begin{array}{l}\text { 14. The feedback I received from the dietitian } \\
\text { helped me understand what I needed to do } \\
\text { to lose weight. }\end{array}$ & $\begin{array}{l}\text { Measurement: patient-provider } \\
\text { communication. (ATA: TMH) } \\
\text { Easy to talk (Richardson) } \\
\text { Item that needs to be addressed: } \\
\text { Confidence in remote physician. } \\
\text { (Demiris) } \\
\text { Patient-professional interaction } \\
\text { (Williams) }\end{array}$ & $\begin{array}{l}\text { How did patients rate the explanations } \\
\text { provided to them of what their problem was } \\
\text { and what was being recommended? (IOM) } \\
\text { My nurse case manager answers my } \\
\text { questions. (Bakken) }\end{array}$ \\
\hline $\begin{array}{l}\text { 15. The feedback I received from the dietitian } \\
\text { helped me understand what I needed to do } \\
\text { to make healthier food choices. }\end{array}$ & $\begin{array}{l}\text { Measurement: patient-provider } \\
\text { communication. (ATA: TMH) } \\
\text { Easy to talk (Richardson) } \\
\text { Item that needs to be addressed: } \\
\text { Confidence in remote physician. } \\
\text { (Demiris) } \\
\text { Patient-professional interaction } \\
\text { (Williams) }\end{array}$ & $\begin{array}{l}\text { How did patients rate the explanations } \\
\text { provided to them of what their problem was } \\
\text { and what was being recommended? (IOM) } \\
\text { My nurse case manager answers my } \\
\text { questions. (Bakken) }\end{array}$ \\
\hline $\begin{array}{l}\text { 16. I was not able to develop a relationship } \\
\text { with the dietitian with video calls. }\end{array}$ & $\begin{array}{l}\text { Measurement: self-reported level of } \\
\text { direct and/or indirect evidence that } \\
\text { the condition of rapport is present } \\
\text { between the patient(s) and the } \\
\text { professional(s)? (ATA: TMH) }\end{array}$ & $\begin{array}{l}\text { How did patients (and family members) } \\
\text { rate the skills and personal manner of the } \\
\text { consultant and the attending personnel } \\
\text { (e.g., primary care physician, nurse } \\
\text { practitioner)? (IOM) } \\
\text { I can easily talk to my health-care provider. } \\
\text { (Yip) }\end{array}$ \\
\hline 17. The dietitian motivated me to lose weight. & $\begin{array}{l}\text { Measurement: patient-provider } \\
\text { communication. (ATA: TMH) }\end{array}$ & $\begin{array}{l}\text { How did patients (and family members) } \\
\text { rate the skills and personal manner of the }\end{array}$ \\
\hline
\end{tabular}




\begin{tabular}{|c|c|c|}
\hline & $\begin{array}{l}\text { Easy to talk (Richardson) } \\
\text { Measurement: self-reported level of } \\
\text { direct and/or indirect evidence that } \\
\text { the condition of rapport is present } \\
\text { between the patient(s) and the } \\
\text { professional(s)? (ATA: TMH) } \\
\text { Patient-professional interaction } \\
\text { (Williams) }\end{array}$ & $\begin{array}{l}\text { consultant and the attending personnel } \\
\text { (e.g., primary care physician, nurse } \\
\text { practitioner)? (IOM) }\end{array}$ \\
\hline $\begin{array}{l}\text { 18. Meeting with the dietitian using video } \\
\text { calls was more convenient than meeting } \\
\text { in person. }\end{array}$ & $\begin{array}{l}\text { Measurement: convenience of } \\
\text { receiving care via this approach } \\
\text { (ATA: TMH) } \\
\text { Convenience (Williams) } \\
\text { Impact on access to health care } \\
\text { (Rahimpour) }\end{array}$ & $\begin{array}{l}\text { I obtain better access to health-care services } \\
\text { by use of telemedicine. (Yip) } \\
\text { Telemedicine saves me time travelling to } \\
\text { hospital or a specialist clinic. (Yip) } \\
\text { Video visits make it easier for me to } \\
\text { contact the nurse. (Bakken) } \\
\text { Video visits save me time. (Bakken) }\end{array}$ \\
\hline $\begin{array}{l}\text { 19. The nutrition coaching phone calls were } \\
\text { useful. }\end{array}$ & $\begin{array}{l}\text { Item: Usefulness of the information } \\
\text { presented (Haozous) } \\
\text { Variable: Usefulness of information } \\
\text { presented (Doorenbos) } \\
\text { Perceived usefulness (Rahimpour) }\end{array}$ & \\
\hline $\begin{array}{l}\text { 20. The video sessions with the dietitian were } \\
\text { useful. }\end{array}$ & $\begin{array}{l}\text { Item: Usefulness of the information } \\
\text { presented (Haozous) } \\
\text { Variable: Usefulness of information } \\
\text { presented (Doorenbos) } \\
\text { Perceived usefulness (Rahimpour) }\end{array}$ & \\
\hline $\begin{array}{l}\text { 21. The frequency of the monthly video } \\
\text { sessions was ideal. }\end{array}$ & & $\begin{array}{l}\text { How did patients rate the convenience of } \\
\text { the encounter, its duration, its timeliness, } \\
\text { and its cost? (IOM) }\end{array}$ \\
\hline $\begin{array}{l}\text { 22. The frequency of the weekly nutrition } \\
\text { coaching phone calls was ideal. }\end{array}$ & & $\begin{array}{l}\text { How did patients rate the convenience of } \\
\text { the encounter, its duration, its timeliness, } \\
\text { and its cost? (IOM) }\end{array}$ \\
\hline
\end{tabular}




\begin{tabular}{|c|c|c|}
\hline $\begin{array}{l}\text { 23. Meeting with the dietitian using video } \\
\text { calls was an effective method of nutrition } \\
\text { care. }\end{array}$ & $\begin{array}{l}\text { Item that needs to be addressed: } \\
\text { Ability to express concerns, ask } \\
\text { questions (Demiris) }\end{array}$ & $\begin{array}{l}\text { How did patients rate the explanations } \\
\text { provided to them of what their problem was } \\
\text { and what was being recommended? (IOM) } \\
\text { I can explain my medical problems well } \\
\text { enough during a video visit. (Bakken) } \\
\text { I feel comfortable communicating with my } \\
\text { health-care provider. (Yip) }\end{array}$ \\
\hline $\begin{array}{l}\text { 24. Overall, I was satisfied with the quality of } \\
\text { nutrition care I received. }\end{array}$ & $\begin{array}{l}\text { Item that needs to be addressed: } \\
\text { Future use (Demiris) } \\
\text { Overall satisfaction (Richardson) } \\
\text { Measurement: patient satisfaction? } \\
\text { (ATA: TMH) } \\
\text { Item: Overall satisfaction with } \\
\text { telehealth (Haozous) } \\
\text { Variable: Satisfaction with telehealth } \\
\text { (Doorenbos) } \\
\text { Patient satisfaction level (Chae) } \\
\text { Overall satisfaction (Williams) } \\
\text { Overall attitude toward the Home } \\
\text { Telecare Management System } \\
\text { (Rahimpour) }\end{array}$ & $\begin{array}{l}\text { Overall, how satisfied were patients with } \\
\text { the telemedicine services they received? } \\
\text { (IOM) } \\
\text { In general, I am satisfied with the } \\
\text { telemedicine system. (Bakken) } \\
\text { Please rate your overall satisfaction level } \\
\text { with TM. (Dick) } \\
\text { Overall, I am satisfied with the quality of } \\
\text { service being provided via telemedicine. } \\
\text { (Yip) } \\
\text { How satisfied are/were you with home } \\
\text { telecare? (Agrell) }\end{array}$ \\
\hline $\begin{array}{l}\text { 25. If I needed nutrition care in the future, I } \\
\text { would like to receive it through video } \\
\text { calls. }\end{array}$ & $\begin{array}{l}\text { Measurement: would patient do this } \\
\text { again? (ATA: TMH) } \\
\text { Item that needs to be addressed: } \\
\text { Preference for type of consultation } \\
\text { (Demiris) } \\
\text { Item: I would use telehealth again } \\
\text { (Haozous) } \\
\text { Would endorse future telemedicine } \\
\text { visits (Callahan) } \\
\text { Intention to use (Rahimpour) }\end{array}$ & $\begin{array}{l}\text { Would patients be willing to use the } \\
\text { telemedicine service again? (IOM) } \\
\text { I will use telemedicine services again. } \\
\text { (Yip) } \\
\text { I would be willing to use home telecare } \\
\text { again. (Agrell) }\end{array}$ \\
\hline
\end{tabular}


Table 3: Questions from the Telenutrition Satisfaction Survey relating to the Technical Aspects with the Original Sources

\begin{tabular}{|c|c|c|c|c|c|c|c|c|c|}
\hline & 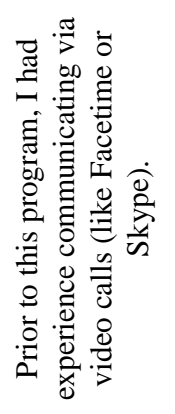 & 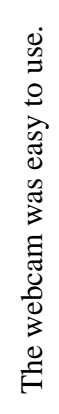 & 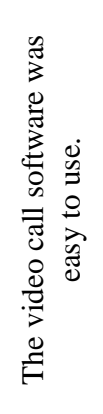 & 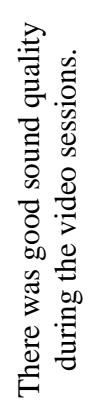 & 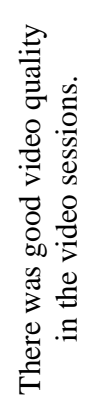 & 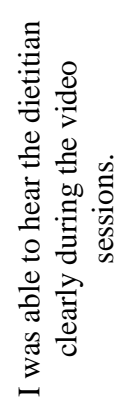 & 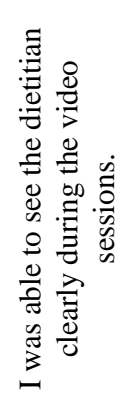 & 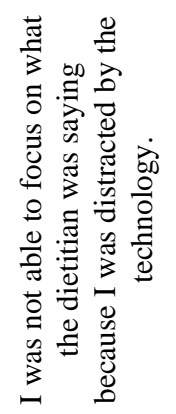 & 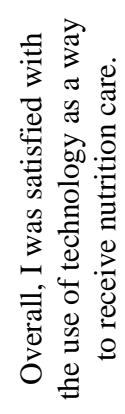 \\
\hline Institute of Medicine (1996) & & & & & & & & & $\mathrm{X}$ \\
\hline $\begin{array}{l}\text { American Telemedicine } \\
\text { Association: Telemental } \\
\text { Health }\end{array}$ & $\mathrm{X}$ & $\mathrm{X}$ & $X$ & & & & & & $\mathrm{X}$ \\
\hline Bakken et al. (2006) & & $\mathrm{X}$ & $\mathrm{X}$ & & & & & & $\mathrm{X}$ \\
\hline Yip et al. (2002) & & & & $\mathrm{X}$ & $\mathrm{X}$ & $\mathrm{X}$ & $\mathrm{X}$ & & $\mathrm{X}$ \\
\hline Dick et al. (1999) & & & & $\mathrm{X}$ & $\mathrm{X}$ & $\mathrm{X}$ & $\mathrm{X}$ & & $\mathrm{X}$ \\
\hline Demiris et al. (2004) & & $\mathrm{X}$ & $\mathrm{X}$ & & & & & & \\
\hline $\begin{array}{l}\text { Clarke and Thiyagarajan } \\
\text { (2008) }\end{array}$ & & $\mathrm{X}$ & $\mathrm{X}$ & $\mathrm{X}$ & $\mathrm{X}$ & $\mathrm{X}$ & $\mathrm{X}$ & & \\
\hline Richardson et al. (2015) & & $\mathrm{X}$ & $\mathrm{X}$ & $\mathrm{X}$ & $\mathrm{X}$ & $\mathrm{X}$ & $\mathrm{X}$ & $\mathrm{X}$ & $\mathrm{X}$ \\
\hline Haozous et al. (2010) & & & & $\mathrm{X}$ & $\mathrm{X}$ & $\mathrm{X}$ & $\mathrm{X}$ & & $\mathrm{X}$ \\
\hline Doorenbos et al. (2010) & & & & $\mathrm{X}$ & $\mathrm{X}$ & $\mathrm{X}$ & $\mathrm{X}$ & & $\mathrm{X}$ \\
\hline \multicolumn{10}{|l|}{ Callahan et al. (1998) } \\
\hline Agrell et al. (2000) & & & & & & & & & $\mathrm{X}$ \\
\hline Chae et al. (2001) & & & & $\mathrm{X}$ & $\mathrm{X}$ & $\mathrm{X}$ & $\mathrm{X}$ & & $\mathrm{X}$ \\
\hline Williams et al. (2001) & & & & & & & & & $\mathrm{X}$ \\
\hline Rahimpour et al. (2008) & & $\mathrm{X}$ & $\mathrm{x}$ & & & & & & $\mathrm{X}$ \\
\hline Parker Oliver et al. (2004) & & $\mathrm{X}$ & $\mathrm{X}$ & $\mathrm{X}$ & $\mathrm{X}$ & $\mathrm{X}$ & $\mathrm{X}$ & & \\
\hline
\end{tabular}




\begin{tabular}{|c|c|c|c|c|c|c|c|c|c|c|c|c|c|c|c|c|}
\hline & 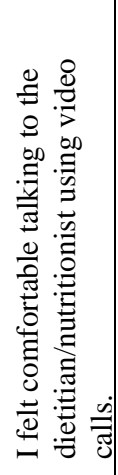 & 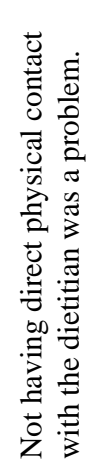 & 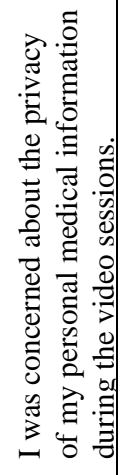 & 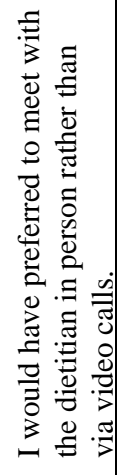 & 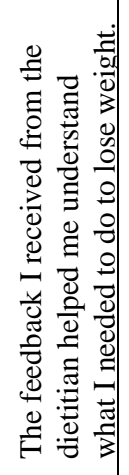 & 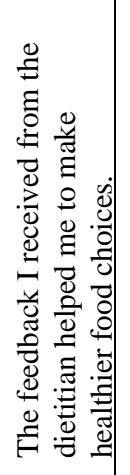 & 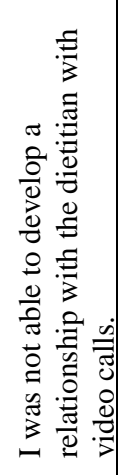 & 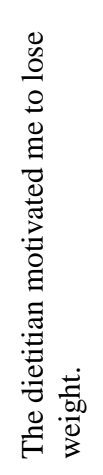 & 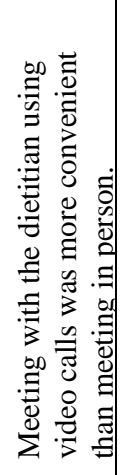 & 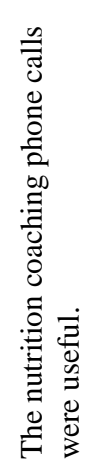 & 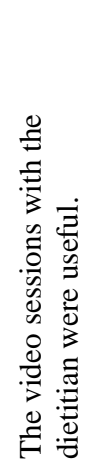 & 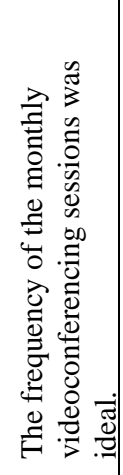 & 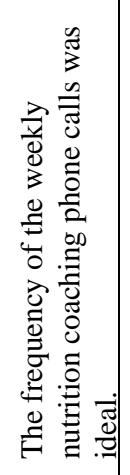 & 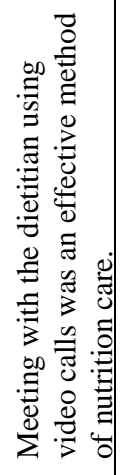 & 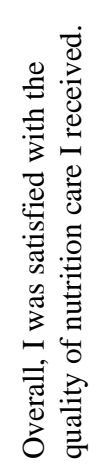 & 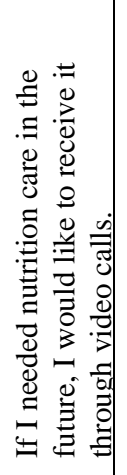 \\
\hline Institute of Medicine (1996) & $\mathrm{X}$ & $\mathrm{X}$ & $\mathrm{X}$ & & $\mathrm{X}$ & $X$ & $\mathrm{X}$ & $\mathrm{X}$ & & & & $\mathrm{X}$ & $\mathrm{X}$ & $\mathrm{X}$ & $\mathrm{X}$ & $\mathrm{X}$ \\
\hline $\begin{array}{l}\text { American Telemedicine } \\
\text { Association: Telemental } \\
\text { Health }\end{array}$ & $\mathrm{X}$ & & & $\mathrm{X}$ & $X$ & $\mathrm{X}$ & $\mathrm{X}$ & $X$ & $X$ & & & & & & $\mathrm{X}$ & $\mathrm{X}$ \\
\hline Bakken et al. (2006) & & $\mathrm{X}$ & $\mathrm{X}$ & & $\mathrm{X}$ & $\mathrm{X}$ & & & $X$ & & & & & $X$ & $X$ & \\
\hline Yip et al. (2002) & $\mathrm{X}$ & & & & & & $X$ & & $X$ & & & & & $X$ & $\mathrm{X}$ & $\mathrm{X}$ \\
\hline Dick et al. (1999) & $\mathrm{X}$ & & $\mathrm{X}$ & & & & & & & & & & & & $\mathrm{X}$ & \\
\hline Demiris et al. (2004) & & $\mathrm{X}$ & $\mathrm{X}$ & & $\mathrm{X}$ & $\mathrm{X}$ & & & & & & & & $\mathrm{X}$ & $\mathrm{X}$ & $\mathrm{X}$ \\
\hline \multicolumn{17}{|l|}{$\begin{array}{l}\text { Clarke and Thiyagarajan } \\
(2008)\end{array}$} \\
\hline Richardson et al. (2015) & & & & & $\mathrm{X}$ & $\mathrm{X}$ & & $\mathrm{X}$ & & & & & & & $\mathrm{X}$ & \\
\hline Haozous et al. (2010) & $\mathrm{X}$ & & & & & & & & & $\mathrm{X}$ & $\mathrm{X}$ & & & & $\mathrm{X}$ & $\mathrm{X}$ \\
\hline Doorenbos et al. (2010) & $\mathrm{X}$ & & & & & & & & & $X$ & $X$ & & & & $X$ & \\
\hline Callahan et al. (1998) & $\mathrm{X}$ & & & $\mathrm{X}$ & & & & & & & & & & & & $\mathrm{X}$ \\
\hline Agrell et al. (2000) & & $\mathrm{X}$ & $\mathrm{X}$ & & & & & & & & & & & & $\mathrm{X}$ & $\mathrm{X}$ \\
\hline Chae et al. (2001) & & & & & & & & & & & & & & & $\mathrm{X}$ & \\
\hline Williams et al. (2001) & $X$ & & & $X$ & $X$ & $X$ & & $X$ & $X$ & & & & & & $X$ & \\
\hline Rahimpour et al. (2008) & & $\mathrm{X}$ & $\mathrm{X}$ & & & & & & $\mathrm{X}$ & $\mathrm{X}$ & $\mathrm{X}$ & & & & $\mathrm{X}$ & $\mathrm{X}$ \\
\hline Parker Oliver et al. (2004) & $\mathrm{X}$ & & & & & & & & & & & & & & & \\
\hline
\end{tabular}


Table 5: Constructs of satisfaction and definitions of each sub-scale of the constructs used in the Telenutrition Satisfaction Survey Constructs with sub-scales

Definition related to our purposes

\section{Technical aspects}

Comfort/Ease of Use

Usability of the technology

Sound Quality

Picture Quality

\section{Professional-patient interaction}

Comfort

Ability to establish rapport

Patient-provider communication

\section{Patient's feelings about} consultation

\section{Comfort}

Privacy

Convenience

Usefulness

Frequency

Preference

\section{Overall satisfaction}

Assessment of the perceived clearness of audio output from the electronic device (i.e., webcam)

Assessment of the perceived clearness of the video image from the electronic device (i.e., webcam)

Feeling of ease associated with nutrition care

Capability of building a trusting relationship

Ability to exchange information effectively between the nutrition care provider and the patient

Feeling of ease associated with nutrition care

Confidentiality of medical information being maintained

Accessing the nutrition care service with little difficulty

The level that the mode of nutrition care was helpful

Occurrence at which the nutrition care service was provided

A greater liking for one alternative over another

Fulfillment of the individual's expectations in relation to the nutrition care received 


\begin{tabular}{|c|c|c|}
\hline Source & Measurement Scale & $\begin{array}{l}\text { Number of Questions } \\
\text { Asked }\end{array}$ \\
\hline Institute of Medicine (1996) & $\mathrm{n} / \mathrm{a}$ & $\mathrm{n} / \mathrm{a}$ \\
\hline $\begin{array}{l}\text { American Telemedicine } \\
\text { Association: Telemental Health }\end{array}$ & $\mathrm{n} / \mathrm{a}$ & $\mathrm{n} / \mathrm{a}$ \\
\hline Bakken et al. (2006) & 5-point Likert scale, strongly disagree to strongly agree & 26 \\
\hline Yip et al. (2002) & 5-point Likert scale, strongly disagree to strongly agree & 14 \\
\hline Dick et al. (1999) & $\begin{array}{l}\text { 3- or 5-point Likert scale response options (completely satisfied, very } \\
\text { satisfied, satisfied, not very satisfied, not at all satisfied), one question } \\
\text { utilized binary response options (yes, no) }\end{array}$ & 13 \\
\hline Demiris et al. (2004) & $\begin{array}{c}13 \text { out of } 14 \text { used questionnaires (no specifics on scale), } 1 \text { of } 14 \text { used } \\
\text { interviews }\end{array}$ & Not provided \\
\hline Clarke and Thiyagarajan (2008) & 27 out of 47 studies in review (59\%) used Likert scales & Not provided \\
\hline Richardson et al. (2015) & $\begin{array}{l}\text { 4-point Likert scale, "poor quality" to "good quality," or "extremely } \\
\text { distracting" to "I didn't notice it at all" }\end{array}$ & 10 \\
\hline Haozous et al. (2010) & 7-point Likert-like scale, not at all true to very true & 6 \\
\hline Doorenbos et al. (2010) & Scores ranged from 1 (lowest) to 5 (highest) & 6 \\
\hline Callahan et al. (1998) & 5-point Likert scale, strongly disagree to strongly agree & 4 \\
\hline Agrell et al. (2000) & Interviews & 34 \\
\hline Chae et al. (2001) & $\begin{array}{l}\text { 5-point scale (ranging from 'much below average', 'below average', } \\
\text { average,' 'better than average', and 'much better than average') }\end{array}$ & 4 \\
\hline Williams et al. (2001) & 64 out of 72 studies in review ( $89 \%$ ) used Likert scales & Range: 1 to 34 \\
\hline Rahimpour et al. (2008) & Focus group interviews & 14 \\
\hline Parker Oliver et al. (2004) & 5-point Likert scale, strongly agree to strongly disagree & 7 \\
\hline
\end{tabular}


Table 7: Final set of questions with their readability level, construct and aspect of each construct in the Telenutrition Satisfaction Survey

Q Statement and Readability Level (Flesch-Kincaid Grade Level)

Construct

Aspect of

Construct

\section{Please rate your satisfaction with the TECHNICAL ASPECTS of your telenutrition experience.}

Q1 Prior to this program, I had experience communicating via video calls

Q1 (like Facetime or Skype). (12.2) ${ }^{\mathrm{a}}$

Q2 The webcam was easy to use. (2.4)

Technical Aspect

Q3 The video call software was easy to use. (5.2)

Q4 There was good sound quality during the video sessions. (7.5)

Q5 There was good video quality during the video sessions. (10.2)

Q6 I was able to hear the dietitian clearly during the video sessions. (8.7)

Q7 I was able to see the dietitian clearly during the video sessions. (8.7)

Q8 I was not able to focus on what the dietitian was saying because I was distracted by the technology. (10.4)

Q9 Overall, I was satisfied with the use of technology as a way to receive nutrition care. (9.8)

Please rate your satisfaction with the NUTRITIONAL CARE aspects of your telenutrition experience.

Q10 I felt comfortable talking to the dietitian using video calls. (10.7)

Not having direct physical contact with the dietitian was a problem.

Q11 (9.0)

Q12 I was concerned about the privacy of my personal medical information during the video sessions. (13.8)

Q13 I would have preferred to meet with the dietitian in person rather than via video calls. (8.3)
Technical Aspect

Technical Aspect

Technical Aspect

Technical Aspect

Technical Aspect

Technical Aspect

Overall Satisfaction

Professional-Patient

Interaction, and Patient's

Feelings about Consultation

Professional-Patient

Interaction

Patient's Feelings about

Consultation

Professional-Patient

Interaction
Comfort/Ease of use

Comfort/Ease of use

Sound quality

Picture quality

Sound quality

Picture quality

Comfort/Ease of

use

Satisfaction

Comfort

Ability to

establish rapport

Privacy

Ability to

establish rapport 
The feedback I received from the dietitian helped me understand what I needed to do to lose weight. (7.8)

Q15 The feedback I received from the dietitian helped me to make healthier food choices. (5.8)

Q16 I was not able to develop a relationship with the dietitian with video calls. (10.0)

Q17 The dietitian motivated me to lose weight. (7.3)

Q18 Meeting with the dietitian using video calls was more convenient than meeting in person. (10.0)

Q19 The nutrition coaching phone calls were useful. (7.3)

Q20 The video sessions with the dietitian were useful. (9.6)

Q21 The frequency of the monthly video sessions was ideal. (8.8)

Q22 The frequency of the weekly nutrition coaching phone calls was ideal. (8.0)

Q23 Meeting with the dietitian using video calls was an effective method of nutrition care. (10.9)

Q24 Overall, I was satisfied with the quality of nutrition care I received. (9.7)

Q25 If I needed nutrition care in the future, I would like to receive it through video calls. (7.6)
Professional-Patient

Interaction

Professional-Patient

Interaction

Professional-Patient

Interaction

Professional-Patient

Interaction

Patient's Feelings about

Consultation

Patient's Feelings about

Consultation

Patient's Feelings about

Consultation

Patient's Feelings about

Consultation

Patient's Feelings about

Consultation

Professional-Patient

Interaction

Overall Satisfaction

Patient's Feelings about

Consultation
Patient-provider communication

Patient-provider communication Ability to establish rapport Ability to establish rapport

Convenience

Usefulness

Usefulness

Frequency

Frequency

Patient-provider communication

Satisfaction

Preference

\footnotetext{
${ }^{\mathrm{a}}$ Question 1 was used as a comparison measure and was not included in satisfaction results.
} 


\section{Participants}

\section{CHAPTER 5: RESULTS}

Of the 27 men included in the sample, the mean age was $59.22(\mathrm{SD}=7.94)$, with a range of 27 years (41 years old to 68 years old). Over half $(15,55.6$ percent) of the participants were between the ages of 60 and 70. From this sample, all 27 were self-identified as non-Hispanic white males, 26 (96.3 percent) were married, 13 (48.1 percent) completed four or more years of college, and 15 (55.6 percent) had an annual household income of greater than $\$ 75,000$. As for employment status, 15 (55.6 percent) were employed full-time for wages, four (14.8 percent) were self-employed, seven (25.9 percent) were retired, and one (3.7 percent) was unable to work.

Table 8 contains participant demographic characteristics.

\section{Technical Difficulties}

A total of 81 video calls were attempted with the twenty-seven participants who are included in this sample (i.e., completed the survey) with 27 calls at each video time point. Problems were broken down depending on the time point which they occurred: difficulties occurring while logging into the Vidyo portal and problems occurring during the video call. These problems were then further broken down into four problem sources: internet connection, server problems, hardware problems due to a mechanical error, or hardware problems due to user error. For breakdown of problem source logging into the Vidyo portal and during the call, see Tables 9 and 10 respectively.

Once the problems occurring during the video calls were classified into their problem source, they were further broken down into either a "major disruption" or a "minor disruption." "Major disruptions" for the participant were defined as interruptions to the video that caused the call to be disrupted, in which action was needed to remedy the technical difficulty and resume the conversation. Examples of major disruptions include: the call being dropped; the video 
freezing for more than ten seconds at one time; losing the video picture of the participant or RDN; the RDN's voice breaking up with the participant being unable to understand; or if the participant's video was lost but the RDN could still hear him. The primary solution for major disruptions was having the RDN, the participant, or both sign out of the Vidyo portal and then re-enter. Over half of the participants (14 of 27, 51.9 percent) experienced major disruptions during the video calls, although major disruptions decreased over the course of the three video calls (10 during call 1, 10 during call 2, and 8 during call 3). "Minor disruptions" for the participant were defined as interruptions in which no action was taken. Examples of minor disruptions included the video freezing for less than ten seconds at one time; having a delay of voice in which voice and mouth were not synced on the video; the video picture being unclear; the sound having an echo; the voice volume raising and lowering; and the screen flashing back and forth between the participant and RDN picture. The most frequent minor disruption that occurred was the picture freezing for less than ten seconds; by the final video call, this disruption was the most frequently occurring, with 90 percent of all minor disruptions being the video freezing briefly. Twenty-six out of 27 participants (96.3 percent) experienced at least one minor or major disruption throughout the course of the three video calls.

\section{Logging in to the Vidyo portal}

Technical difficulties occurred throughout the course of the study when participants attempted to $\log$ in to the Vidyo portal, but these problems were able to be overcome by quick troubleshooting or by employing alternate means of conducting the interview. Of the 81 total calls, the first two video calls attempted with one of the participants were unable to be completed over videoconferencing due to internet connection problems, so the calls were held over the telephone. Thus, only 79 calls conducted contained at least some video connection. For each call, 
multiple participants faced no issues logging in: 18 participants (66.7 percent) for call one, 12 participants (44.4 percent) for call two, and 11 participants (40.1 percent) for call three. Participants generally faced technical difficulties logging into the Vidyo portal during at least one of the video calls, with 22 of 27 participants (81 percent) experiencing at least at one technical difficulty logging into this portal over the course of the study.

The most frequent type of problems encountered were mechanical errors dealing with the computer hardware. The main mechanical problem dealt with the RDN being unable to hear the participant initially when he logged into the Vidyo portal. This problem was typically resolved in less than one minute, and the RDN was able to hear the participant and conduct the call as intended. However, eight times throughout the intervention ( 8 of 81 calls, 9.9 percent; affecting 6 of 27 participants, 22.2 percent), this problem was unable to be fixed after multiple troubleshooting attempts that had worked when the problem had occurred with other participants. Thus, these calls were held via video and telephone simultaneously so the participant and RDN could see each other over video but have audio via telephone.

Some other issues that occurred during the initiation of calls were the participant calling or emailing to say that he was having issues logging in; the participant being unable to hear the RDN; and the RDN being unable to see or hear the participant even though the participant could see and hear the RDN. These issues were each resolved with an explanation by the RDN or by contacting technology support staff, with participant permission. The total average time taken to get the video to work was 2 minutes, 8.9 seconds for both calls one and two, and 2 minutes, 11.1 seconds for call three.

Table 11 provides a full breakdown of problems occurring while logging in to the Vidyo portal. 


\section{During the video call}

Technical difficulties also occurred during video calls throughout the course of the study; these problems were also overcome by quick troubleshooting or by employing alternate means of conducting the interview. Over one-third of the participants faced no issues during the video calls, with thirteen participants experiencing no problems during the first set of calls, ten participants experiencing no difficulties during the second set of calls, and twelve participants experiencing no difficulties during the third set of calls. Of the four problem sources, the majority of the problems occurring were hardware problems due to a mechanical error: 29 of 31 (93.5 percent) technical difficulties were a result of this problem during the first set of video calls, 25 of 26 ( 96.2 percent) during the second, and 38 of 40 during the third (95.0 percent).

After successful initial video connection, a total of ten calls were dropped over the course of the intervention with the number of calls dropped decreasing over time: six calls dropped during the first video call, four during the second, and one during the third. Of the six dropped during the first call, two participants had two dropped calls each, and two participants had one dropped call each. Five of these calls were the result of mechanical errors, while one was due to a server error. Regarding the server error, the company who provided the internet service being used at the location of the RDN was cyber attacked, causing large portions of the network to be shut down. This call was then completed over telephone, per participant request. This issue occurred during the first video call, and the participant later had two successful video calls with no issues. The other dropped calls were successfully reconnected within one minute of losing the video, and the call was able to be completed over video.

The four dropped calls during the second video call all occurred to the same participant. This participant had experienced no issues during the first video call. All four dropped calls were 
the result of hardware problems due to mechanical errors. The video picture and sound were both dropped four times within the first eight minutes of the call. Each time the call was dropped, the participant was able to reconnect to the video within one minute; however, due to the disruptive nature of the continuously dropped calls as the nutrition counseling was ongoing, the participant and RDN agreed to complete the remainder of the call over telephone. This participant did not have any technical issues during his third video call.

The one dropped call during the third video call was due to hardware problems dealing with user error. The participant's computer was scheduled to restart during the video call, resulting in a loss of the video picture. Once the computer restarted, the participant was able to successfully reconnect, and the video call was completed with no further issues.

Table 12 provides a full breakdown of problems occurring during the video call.

\section{Survey}

Survey results demonstrate participants' satisfaction with the intervention. Table 13 provides a breakdown of each survey question with the Likert response and percentage. A high level of satisfaction was found with both the technical aspects and the nutritional care aspects of the telenutrition experience with a mean of $4.30(\mathrm{SD}=0.48)$ out of 5 . The lowest rated mean score on the survey was $3.96(\mathrm{SD}=0.87)$ out of 5 for the statement, "The webcam was easy to use;" every other satisfaction question was rated at least a 4 on the 5 point scale. The highest mean score was rated 4.63 ( $\mathrm{SD}=0.69$ ) out of 5 for the item, "Overall, I was satisfied with the quality of nutrition care I received." Table 14 provides a breakdown of mean (SD) of all survey questions.

Each of the four constructs had an average score of greater than 4 out of 5, when broken down by survey construct. Table 15 provides the distribution of the overall satisfaction survey scores and the score break down by construct. Between the four survey constructs, the range of 
mean scores was $4.19(\mathrm{SD}=0.61)$ to $4.41(\mathrm{SD}=0.76)$ with technical aspects being rated the lowest and overall satisfaction the highest. For the seven questions on the survey that dealt with technical aspects of the telenutrition experience, the mean score was $4.19(\mathrm{SD}=0.61)$ out of 5. For the eight questions regarding professional-patient interaction, the mean score was 4.38 $(\mathrm{SD}=0.55)$ out of 5. For the eight questions regarding the patient's feelings about the consultation, the mean score was $4.33(\mathrm{SD}=0.55)$ out of 5 . For the two questions measuring overall satisfaction, the mean score was $4.41(\mathrm{SD}=0.76)$ out of 5. Based on comments provided in the open-ended questions relating to the technology aspects of the telenutrition experience, one participant who rated the technology aspects 2.63 out of 5 , stated that despite having issues on several occasions with video and audio loss, he and the RDN were able to continue the calls using simple troubleshooting or by employing alternate means and that he was overall satisfied.

No significant differences were found in survey results when comparing different demographics of age, income level, education level, or employment status. Regarding age, the youngest and oldest age ranges had similar mean satisfaction levels $(\mathrm{M}=4.37, \mathrm{SD}=0.46$ and $\mathrm{M}=4.36, \mathrm{SD}=0.41$, respectively). The middle group of ages had a lower mean satisfaction level $(\mathrm{M}=4.17, \mathrm{SD}=0.63)$, but this difference was not significant $(p=0.66)$. When comparing income level, the mean survey score of participants with an annual income level of $\$ 75,000$ or greater (M4.27, $\mathrm{SD}=0.13$ ) had no significant differences than the score of participants with an income level less than $\$ 75,000(\mathrm{M}=4.26, \mathrm{SD}=0.15)(p=0.95)$. There were also no significant differences $(p=0.26)$ in satisfaction based on the participants' highest grade of education completed.

Satisfaction levels were similar between those who completed grade 12 or GED (M=4.04, $\mathrm{SD}=0.31)$, one to three years of college $(\mathrm{M}=4.40, \mathrm{SD}=0.49)$, or who were college graduates $(\mathrm{M}=4.39, \mathrm{SD}=0.53)$. When comparing employment status, participants who were currently 
working for wages (i.e., employed full-time or self-employed) had a mean satisfaction score of 4.27 ( $\mathrm{SD}=0.51$ ), while participants who were currently not employed and receiving wages (i.e., retired or unable to work) had a mean satisfaction score of $4.37(\mathrm{SD}=0.42)$; no significant differences were found between these two employment brackets $(p=0.62)$.

When comparing survey results with technical aspects, no significant differences in level of satisfaction were based on facing technical problems during the videoconferencing. Participants who were unable to log into the Vidyo portal and were unable to fix this problem on at least one occasion had no significant difference in satisfaction level when compared to participants who had no technical issues $(p=0.87)$. When logging into the Vidyo portal, the six participants who faced an issue that was unable to be fixed over video rated their satisfaction slightly higher $(\mathrm{M}=4.33, \mathrm{SD}=0.40)$ than participants who either faced no issues logging into the Vidyo portal or those whose problems were able to be corrected $(\mathrm{M}=4.30, \mathrm{SD}=0.51)$, but the difference was not significant. Participants experiencing at least one major problem during the videoconferencing sessions also exhibited no significant difference in satisfaction level compared to participants who experienced no problems $(p=0.96)$. If the participant experienced any major problems that disrupted the call during the videoconferencing sessions, the mean satisfaction score was $4.30(\mathrm{SD}=0.44)$, while those who did not experience any major issues had a similar mean score with $4.31(\mathrm{SD}=0.54)$. Furthermore, no significant difference in satisfaction level was found based on the level of prior videoconferencing experience when comparing all five levels of Likert responses from strongly disagree to strongly agree $(p=0.13)$. Participants who strongly agreed that they had prior experience rated satisfaction the highest; therefore, when these participants who strongly agreed were compared with the rest of the sample, mean scores 
were significantly higher $(p<0.0001)$ for those participants who strongly agreed $(M=4.79$, $\mathrm{SD}=0.05)$ than the rest of the sample $(\mathrm{M}=4.16, \mathrm{SD}=0.45)$.

Table 8 lists the average satisfaction score broken down by each comparison variable. Table 16 provides analysis of variance results of the satisfaction survey for the comparisons age group, education level, and prior videoconferencing experience, and Table 17 provides t-test results of the satisfaction survey for the comparisons income level, employment status, Vidyo portal issues, major disruptions during the video call, and the binary comparison of prior videoconferencing experience. 


\begin{tabular}{|c|c|c|c|c|}
\hline & $\mathrm{n}$ & $\%$ & Mean & SD \\
\hline \multicolumn{5}{|l|}{ Race } \\
\hline Non-Hispanic white & 27 & 100 & 4.30 & 0.48 \\
\hline \multicolumn{5}{|l|}{ Marital Status } \\
\hline Married & 26 & 96.3 & 4.30 & 0.49 \\
\hline Never married & 1 & 3.7 & 4.38 & - \\
\hline \multicolumn{5}{|l|}{ Age Range (years) } \\
\hline $40-49$ & 4 & 14.8 & 4.37 & 0.46 \\
\hline $50-59$ & 8 & 29.6 & 4.17 & 0.63 \\
\hline $60-70$ & 15 & 55.6 & 4.36 & 0.41 \\
\hline \multicolumn{5}{|l|}{ Annual Household Income Level } \\
\hline Up to $\$ 74,999$ & 10 & 37.0 & 4.26 & 0.15 \\
\hline$\$ 75,000$ or more & 15 & 55.6 & 4.27 & 0.13 \\
\hline Prefer not to say & 1 & 3.7 & - & - \\
\hline Missing & 1 & 3.7 & - & - \\
\hline \multicolumn{5}{|l|}{ Education Level Completed } \\
\hline Grade 12 or GED & 7 & 25.9 & 4.04 & 0.31 \\
\hline College 1 year to 3 years & 7 & 25.9 & 4.40 & 0.49 \\
\hline College 4 years or more & 13 & 48.1 & 4.39 & 0.53 \\
\hline \multicolumn{5}{|l|}{ Employment Status } \\
\hline Employed for wages (full-time) & 15 & 55.6 & \multirow{2}{*}{4.27} & \multirow{2}{*}{0.51} \\
\hline Self-employed & 4 & 14.8 & & \\
\hline Retired & 7 & 25.9 & \multirow{2}{*}{4.37} & \multirow[b]{2}{*}{0.42} \\
\hline Unable to work & 1 & 3.7 & & \\
\hline \multicolumn{5}{|l|}{ Unable to Fix Issue Logging Into } \\
\hline \multicolumn{5}{|l|}{ Vidyo } \\
\hline Yes & 6 & 22.2 & 4.33 & 0.40 \\
\hline No & 21 & 77.8 & 4.30 & 0.51 \\
\hline \multicolumn{5}{|l|}{ Experienced Major Issues During } \\
\hline \multicolumn{5}{|l|}{ Video } \\
\hline Yes & 14 & 51.9 & 4.30 & 0.44 \\
\hline No & 13 & 48.1 & 4.31 & 0.54 \\
\hline \multicolumn{5}{|c|}{$\begin{array}{l}\text { Prior to this program, I had experience } \\
\text { communicating via video calls. }\end{array}$} \\
\hline Strongly Disagree & 6 & 22.2 & 4.28 & 0.40 \\
\hline Disagree & 4 & 14.8 & 4.08 & 0.37 \\
\hline Neutral & 4 & 14.8 & 4.20 & 0.49 \\
\hline Agree & 9 & 33.3 & 4.09 & 0.53 \\
\hline Strongly Agree & 4 & 14.8 & 4.79 & 0.05 \\
\hline
\end{tabular}


Table 9: Technical issues faced during 81 attempted video calls logging into the Vidyo portal, broken down by problem source

\begin{tabular}{lccc} 
& $\begin{array}{c}\text { First Video } \\
\text { Call }\end{array}$ & $\begin{array}{c}\text { Second Video } \\
\text { Call }\end{array}$ & $\begin{array}{c}\text { Third Video } \\
\text { Call }\end{array}$ \\
\cline { 1 - 2 } & 4 & Number of times & \multicolumn{2}{c}{} \\
Internet connection & 1 & 1 & 0 \\
$\quad$ Unable to fix problem & 1 & 1 & $\mathrm{n} / \mathrm{a}$ \\
Server problems & 0 & 0 & 0 \\
Hardware problem: mechanical error & 8 & 11 & 14 \\
$\quad$ Unable to fix problem & 1 & 2 & 3 \\
Hardware problem: user error & 0 & 4 & 4 \\
Number of participants with no issues & 18 & 12 & 11 \\
Average time to get video to work & 2 minutes, & 2 minutes, & 2 minutes, \\
& 8.9 seconds & 8.9 seconds & 11.1 seconds \\
Range of time to get video to work (minutes) & $0-14$ & $0-12$ & $0-15$ \\
\hline
\end{tabular}




\begin{tabular}{lccc}
\hline $\begin{array}{l}\text { Table 10: Technical issues faced during 81 attempted video calls, broken down by problem } \\
\text { source }^{\mathrm{a}}\end{array}$ & $\begin{array}{c}\text { First Video } \\
\text { Call }\end{array}$ & $\begin{array}{c}\text { Second } \\
\text { Video Call }\end{array}$ & $\begin{array}{c}\text { Third Video } \\
\text { Call }\end{array}$ \\
\hline Internet connection & 1 & Number of times & \\
Server problems & 1 & 1 & 0 \\
Hardware problem: mechanical error & 29 & 0 & 0 \\
$\quad$ Major disruption, action required & 10 & 26 & 38 \\
Minor disruption, no action taken & 19 & 10 & 8 \\
Hardware problem: user error & 0 & 0 & 30 \\
Number of participants with no issues & 13 & 10 & 2 \\
\hline
\end{tabular}

${ }^{a}$ Note: Some participants had multiple problems occur during a single call, giving a higher number of the number of times a problem occurred than the number of participants 


\begin{tabular}{|c|c|c|c|c|c|}
\hline Technical Issue & $\begin{array}{l}\text { Video call } \\
1\end{array}$ & $\begin{array}{l}\text { Video call } \\
\quad 2\end{array}$ & $\begin{array}{l}\text { Video call } \\
3\end{array}$ & Overall & $\begin{array}{l}\text { Problem } \\
\text { Source }\end{array}$ \\
\hline & & \multicolumn{2}{|c|}{ Number of times } & $\longrightarrow$ & \\
\hline Total calls & 27 & 27 & 27 & 81 & - \\
\hline No issues & 18 & 12 & 11 & 41 & - \\
\hline $\begin{array}{l}\text { Unable to establish } \\
\text { video }\end{array}$ & 1 & 1 & 0 & 2 & $\begin{array}{l}\text { Internet } \\
\text { connection }\end{array}$ \\
\hline $\begin{array}{l}\text { RDN unable to hear } \\
\text { participant/participant's } \\
\text { voice was muffled } \\
\text { initially }\end{array}$ & 5 & 10 & 11 & 26 & $\begin{array}{l}\text { Hardware, } \\
\text { mechanical }\end{array}$ \\
\hline $\begin{array}{l}\text { RDN unable to see } \\
\text { participant; participant } \\
\text { able to see RDN }\end{array}$ & 1 & 0 & 0 & 1 & $\begin{array}{l}\text { Hardware, } \\
\text { mechanical }\end{array}$ \\
\hline $\begin{array}{l}\text { Participant unable to } \\
\text { hear RDN initially }\end{array}$ & 2 & 0 & 1 & 3 & $\begin{array}{l}\text { Hardware, } \\
\text { mechanical }\end{array}$ \\
\hline $\begin{array}{l}\text { Participant called/e- } \\
\text { mailed saying he was } \\
\text { having issues }\end{array}$ & 0 & 3 & 1 & 4 & $\begin{array}{l}\text { Hardware, } \\
\text { user }\end{array}$ \\
\hline $\begin{array}{l}\text { RDN explained how to } \\
\text { turn on microphone } \\
\text { and video }\end{array}$ & 0 & 1 & 0 & 1 & $\begin{array}{l}\text { Hardware, } \\
\text { user }\end{array}$ \\
\hline $\begin{array}{l}\text { RDN walked } \\
\text { participant through } \\
\text { process of downloading } \\
\text { and installing Vidyo } \\
\text { software }\end{array}$ & 0 & 0 & 2 & 2 & $\begin{array}{l}\text { Hardware, } \\
\text { user }\end{array}$ \\
\hline $\begin{array}{l}\text { Participant could hear } \\
\text { RDN but not see RDN }\end{array}$ & 0 & 0 & 2 & 2 & $\begin{array}{l}\text { Hardware, } \\
\text { mechanical } \\
\text { Video } 2 .\end{array}$ \\
\hline $\begin{array}{l}\text { RDN unable to hear or } \\
\text { see participant }\end{array}$ & 0 & 1 & 1 & 2 & $\begin{array}{c}\text { Hardware, } \\
\text { mechanical } \\
\text { Video 3: } \\
\text { Hardware, } \\
\text { user }\end{array}$ \\
\hline Unable to fix problem & 2 & 3 & 3 & 8 & - \\
\hline $\begin{array}{l}\text { Average length of time } \\
\text { to get video to work } \\
\text { (minutes) }\end{array}$ & $\begin{array}{l}2 \text { minutes, } \\
8.9 \text { seconds }\end{array}$ & $\begin{array}{l}2 \text { minutes, } \\
8.9 \text { seconds }\end{array}$ & $\begin{array}{l}2 \text { minutes, } \\
11.1 \\
\text { seconds }\end{array}$ & - & - \\
\hline $\begin{array}{l}\text { Range of length of time } \\
\text { to get video to work } \\
\text { (minutes) }\end{array}$ & $0-14$ & $0-12$ & $0-15$ & - & - \\
\hline
\end{tabular}


Table 12: Types of technical issues during the video calls broken down by time of call for 81 video calls

\begin{tabular}{|c|c|c|c|c|c|}
\hline Technical Issue & Video call 1 & Video call 2 & Video call 3 & Overall & $\begin{array}{l}\text { Problem } \\
\text { Source }\end{array}$ \\
\hline & & \multicolumn{2}{|c|}{ Number of times } & $\longrightarrow$ & \\
\hline Total calls & 27 & 27 & 27 & 81 & - \\
\hline No issues & 13 & 10 & 12 & 35 & - \\
\hline $\begin{array}{l}\text { Unable to establish } \\
\text { video }\end{array}$ & 1 & 1 & 0 & 2 & $\begin{array}{c}\text { Internet } \\
\text { connection }\end{array}$ \\
\hline Video froze & 11 & 8 & $29^{\mathrm{a}}$ & 48 & $\begin{array}{l}\text { Hardware, } \\
\text { mechanical }\end{array}$ \\
\hline Delay of voice & 5 & 3 & 0 & 8 & $\begin{array}{l}\text { Hardware, } \\
\text { mechanical }\end{array}$ \\
\hline Picture unclear/fuzzy & 2 & 4 & 1 & 7 & $\begin{array}{l}\text { Hardware, } \\
\text { mechanical }\end{array}$ \\
\hline Video had an echo & 1 & 1 & 1 & 3 & $\begin{array}{l}\text { Hardware, } \\
\text { mechanical }\end{array}$ \\
\hline Call dropped & 6 & 4 & 1 & 11 & $\begin{array}{c}\text { 1: Server, } \\
9: \\
\text { Hardware, } \\
\text { mechanical } \\
1: \\
\text { Hardware, } \\
\text { user }\end{array}$ \\
\hline $\begin{array}{l}\text { RDN voice breaking up } \\
\text { for participant }\end{array}$ & 2 & 1 & 1 & 4 & $\begin{array}{l}\text { Hardware, } \\
\text { mechanical }\end{array}$ \\
\hline $\begin{array}{l}\text { Participant voice } \\
\text { volume up and down }\end{array}$ & 1 & 0 & 1 & 2 & $\begin{array}{c}\text { Hardware, } \\
\text { user }\end{array}$ \\
\hline $\begin{array}{l}\text { Participant lost video } \\
\text { but could still hear } \\
\text { RDN }\end{array}$ & 2 & 1 & 5 & 8 & $\begin{array}{l}\text { Hardware, } \\
\text { mechanical }\end{array}$ \\
\hline $\begin{array}{l}\text { Participant unable to } \\
\text { see RDN, but RDN } \\
\text { could see him }\end{array}$ & 0 & 3 & 0 & 3 & $\begin{array}{l}\text { Hardware, } \\
\text { mechanical }\end{array}$ \\
\hline $\begin{array}{l}\text { Participant screen } \\
\text { flashed back and forth } \\
\text { between his picture and } \\
\text { RDN picture }\end{array}$ & 0 & 0 & 1 & 1 & $\begin{array}{c}\text { Hardware, } \\
\text { user }\end{array}$ \\
\hline $\begin{array}{l}\text { Total number of } \\
\text { issues }\end{array}$ & 31 & 26 & 40 & 96 & - \\
\hline
\end{tabular}

${ }^{a}$ Of the 29 times frozen during the third video, two were major disruptions and 27 were minor disruptions. 
Table 13: Survey Results broken down by individual questions from the Telenutrition

Satisfaction Survey $(\mathrm{N}=27)$

Q Statement, Responses

Q1 Prior to this program, I had experience communicating via video calls. ${ }^{\mathrm{a}}$

Strongly Disagree

Disagree

Neutral

$\mathrm{n}$

$\%$

Agree

Strongly Agree

22.2

14.8

14.8

33.3

14.8

Q2 The webcam was easy to use.

Strongly Disagree

3.85

Disagree

0

Neutral

15.4

Agree

57.7

Strongly Agree

Missing

23.1

15

Q3 The video call software was easy to use.

Strongly Disagree

Disagree

Neutral

3.70

Agree

0

Strongly Agree

66.7

25.9

Q4 There was good sound quality during the video sessions.

Strongly Disagree

Disagree

0

Neutral

7.4

Agree

0

Strongly Agree

$\begin{array}{ll}14 & 51.9 \\ 11 & 40.7\end{array}$

Q5 There was good video quality during the video sessions.

Strongly Disagree

0

Disagree

0

$1 \quad 3.70$

Neutral

0

0

Agree

Strongly Agree

$11 \quad 40.7$

I was able to hear the dietitian clearly during the video sessions.

Strongly Disagree

Disagree

Neutral

Agree

Strongly Agree

I was able to see the dietitian clearly during the video sessions.

Strongly Disagree

Disagree 
Neutral $\quad 0$

Q8 I was not able to focus on what the dietitian was saying because I was distracted by the technology.

Strongly Disagree

Disagree

12

Neutral

Agree

Strongly Agree

Q9 Overall, I was satisfied with the use of technology as a way to receive nutrition care.

Strongly Disagree

Disagree

Neutral

Agree

Strongly Agree

Missing

Q10 I felt comfortable talking to the dietitian using video calls.

Strongly Disagree

Disagree

Neutral

Agree

Strongly Agree

Q11 Not having direct physical contact with the dietitian was a problem.

\section{Strongly Disagree}

Disagree

Neutral

Agree

Strongly Agree

Q12 I was concerned about the privacy of my personal medical information during the video sessions.

$\begin{array}{lr}\text { Strongly Disagree } & 12 \\ \text { Disagree } & 13\end{array}$

Disagree

Neutral

Agree

I would have preferred to meet with the dietitian in person rather than via video calls.

\section{Strongly Disagree}

Disagree

Neutral

Agree

Strongly Agree

Missing 
Q14 The feedback I received from the dietitian helped me understand what I needed to do to lose weight.

$\begin{array}{lcc}\text { Strongly Disagree } & 0 & 0 \\ \text { Disagree } & 1 & 3.70 \\ \text { Neutral } & 0 & 0 \\ \text { Agree } & 9 & 33.3 \\ \text { Strongly Agree } & 17 & 63.0\end{array}$

Q15 The feedback I received from the dietitian helped me to make healthier food choices.

Strongly Disagree $\quad 0 \quad 0$

$\begin{array}{lll}\text { Disagree } & 1 & 3.7\end{array}$

Neutral $\quad 00$

$\begin{array}{lll}\text { Agree } & 8 & 29.6\end{array}$

$\begin{array}{lll}\text { Strongly Agree } & 18 & 66.7\end{array}$

Q16 I was not able to develop a relationship with the dietitian with video calls.

$\begin{array}{lll}\text { Strongly Disagree } & 12 & 44.4\end{array}$

$\begin{array}{llll}\text { Disagree } & 11 & 40.7\end{array}$

Neutral $\quad 000$

$\begin{array}{lll}\text { Agree } & 3 & 11.1\end{array}$

$\begin{array}{lll}\text { Strongly Agree } & 1 & 3.70\end{array}$

Q17 The dietitian motivated me to lose weight.

Strongly Disagree $\quad 000$

$\begin{array}{lll}\text { Disagree } & 1 & 3.70\end{array}$

$\begin{array}{lll}\text { Neutral } & 1 & 3.70\end{array}$

Agree

33.3

$\begin{array}{lll}\text { Strongly Agree } & 16 & 59.3\end{array}$

Q18 Meeting with the dietitian using video calls was more convenient than meeting in person.

Strongly Disagree

Disagree

Neutral

Agree

Strongly Agree

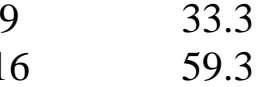

The nutrition coaching phone calls were useful.

$\begin{array}{lll}\text { Strongly Disagree } & 0 & 0\end{array}$

$\begin{array}{lll}\text { Disagree } & 1 & 3.70\end{array}$

Neutral $\quad 0 \quad 0$

$\begin{array}{lll}\text { Agree } & 11 & 40.7\end{array}$

$\begin{array}{lll}\text { Strongly Agree } & 15 & 55.6\end{array}$

Q20 The video sessions with the dietitian were useful.

Strongly Disagree $\quad 0$

Disagree $\quad 1$

Neutral 0

Agree 10

37.0

$\begin{array}{lll}\text { Strongly Agree } & 16 & 59.3\end{array}$ 
Q21 The frequency of the monthly video sessions was ideal.

Strongly Disagree

$\begin{array}{cc}0 & 0 \\ 0 & 0 \\ 5 & 18.5 \\ 10 & 37.0 \\ 12 & 44.4\end{array}$

Disagree

Neutral

Agree

Strongly Agree

$12 \quad 44.4$

Q22 The frequency of the weekly nutrition coaching phone calls was ideal.

Strongly Disagree

Disagree

Neutral

Agree

Strongly Agree

Missing

Q23 Meeting with the dietitian using video calls was an effective method of nutrition care.

Strongly Disagree

Disagree

Neutral

Agree

Strongly Agree

$0 \quad 0$

$0 \quad 0$

$\begin{array}{ll}4 & 15.4\end{array}$

$8 \quad 30.8$

$14 \quad 53.8$

1

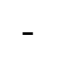

verall, I was satisfied with the quality of nutrition care I

Q24 received.

Strongly Disagree

Disagree

Neutral

13.70

$2 \quad 7.40$

$12 \quad 44.4$

$12 \quad 44.4$

Agree

Strongly Agree

If I needed nutrition care in the future, I would like to receive it through video calls.

Strongly Disagree $\quad \begin{array}{ll}0 & 0\end{array}$

Disagree

$1 \quad 3.85$

Neutral

$6 \quad 23.1$

Agree

$11 \quad 42.3$

Strongly Agree

Missing

$\begin{array}{ll}8 & 30.8\end{array}$

${ }^{\mathrm{a} Q u e s t i o n} 1$ was used as a comparison measure and was not included in satisfaction results. 


\begin{tabular}{|c|c|c|c|c|c|}
\hline Q & Statement & $\mathrm{N}$ & $\begin{array}{l}\text { Mean } \\
(\mathrm{SD})^{\mathrm{a}}\end{array}$ & $\begin{array}{l}\text { Upper } \\
95 \% \\
\text { Mean }\end{array}$ & $\begin{array}{l}\text { Lower } \\
95 \% \\
\text { Mean }\end{array}$ \\
\hline Q1 & $\begin{array}{l}\text { Prior to this program, I had experience } \\
\text { communicating via video calls (like Facetime } \\
\text { or Skype). }{ }^{\text {b }}\end{array}$ & 27 & $3.03(1.43)$ & 3.60 & 2.47 \\
\hline Q2 & The webcam was easy to use. & 26 & $3.96(0.87)$ & 4.31 & 3.61 \\
\hline Q3 & The video call software was easy to use. & 27 & $4.07(0.87)$ & 4.42 & 3.73 \\
\hline Q4 & $\begin{array}{l}\text { There was good sound quality during the } \\
\text { video sessions. }\end{array}$ & 27 & $4.26(0.81)$ & 4.58 & 3.94 \\
\hline Q5 & $\begin{array}{l}\text { There was good video quality during the video } \\
\text { sessions. }\end{array}$ & 27 & $4.33(0.68)$ & 4.60 & 4.06 \\
\hline Q6 & $\begin{array}{l}\text { I was able to hear the dietitian clearly during } \\
\text { the video sessions. }\end{array}$ & 27 & $4.26(0.81)$ & 4.58 & 3.94 \\
\hline Q7 & $\begin{array}{l}\text { I was able to see the dietitian clearly during } \\
\text { the video sessions. }\end{array}$ & 27 & $4.41(0.69)$ & 4.68 & 4.13 \\
\hline Q8 & $\begin{array}{l}\text { I was not able to focus on what the dietitian } \\
\text { was saying because I was distracted by the } \\
\text { technology. }\end{array}$ & 27 & $4.04(1.19)$ & 4.51 & 3.57 \\
\hline Q9 & $\begin{array}{l}\text { Overall, I was satisfied with the use of } \\
\text { technology as a way to receive nutrition care. }\end{array}$ & 25 & $4.28(0.98)$ & 4.68 & 3.88 \\
\hline Q10 & $\begin{array}{l}\text { I felt comfortable talking to the dietitian using } \\
\text { video calls. }\end{array}$ & 27 & $4.56(0.70)$ & 4.83 & 4.28 \\
\hline Q11 & $\begin{array}{l}\text { Not having direct physical contact with the } \\
\text { dietitian was a problem. }\end{array}$ & 27 & $4.37(0.69)$ & 4.64 & 4.10 \\
\hline Q12 & $\begin{array}{l}\text { I was concerned about the privacy of my } \\
\text { personal medical information during the video } \\
\text { sessions. }\end{array}$ & 27 & $4.30(0.87)$ & 4.64 & 3.95 \\
\hline Q13 & $\begin{array}{l}\text { I would have preferred to meet with the } \\
\text { dietitian in person rather than via video calls. }\end{array}$ & 26 & $4.04(0.66)$ & 4.31 & 3.77 \\
\hline Q14 & $\begin{array}{l}\text { The feedback I received from the dietitian } \\
\text { helped me understand what I needed to do to } \\
\text { lose weight. }\end{array}$ & 27 & $4.56(0.70)$ & 4.83 & 4.28 \\
\hline Q15 & $\begin{array}{l}\text { The feedback I received from the dietitian } \\
\text { helped me to make healthier food choices. }\end{array}$ & 27 & $4.59(0.69)$ & 4.87 & 4.32 \\
\hline Q16 & $\begin{array}{l}\text { I was not able to develop a relationship with } \\
\text { the dietitian with video calls. }\end{array}$ & 27 & $4.11(1.12)$ & 4.55 & 3.67 \\
\hline Q17 & The dietitian motivated me to lose weight. & 27 & $4.48(0.75)$ & 4.78 & 4.18 \\
\hline
\end{tabular}


Q18 Meeting with the dietitian using video calls was more convenient than meeting in person.

Q19 The nutrition coaching phone calls were useful.

Q20 The video sessions with the dietitian were useful.

Q21 The frequency of the monthly video sessions was ideal.

Q22 The frequency of the weekly nutrition coaching phone calls was ideal.

Q23 Meeting with the dietitian using video calls was an effective method of nutrition care.

Q24 Overall, I was satisfied with the quality of nutrition care I received.

Q25 If I needed nutrition care in the future, I would like to receive it through video calls. $\begin{array}{llll}27 & 4.11(0.85) & 4.45 & 3.78\end{array}$

$27 \quad 4.48(0.70) \quad 4.76 \quad 4.20$

$27 \quad 4.52(0.70) \quad 4.80 \quad 4.24$

$27 \quad 4.25(0.76) \quad 4.56 \quad 3.96$

$26 \quad 4.38(0.75) \quad 4.69 \quad 4.08$

$27 \quad 4.30(0.78) \quad 4.60 \quad 3.99$

$27 \quad 4.63(0.69) \quad 4.90 \quad 4.36$

$26 \quad 4.00(0.85) \quad 4.34 \quad 3.66$

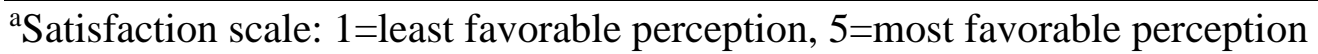

${ }^{\mathrm{b}}$ Question 1 was used as a comparison measure and was not included in satisfaction results. 


\begin{tabular}{|c|c|c|c|c|c|c|}
\hline & $\begin{array}{l}\text { Questions } \\
\text { included }\end{array}$ & Mean & $\mathrm{SD}$ & $\begin{array}{l}\text { Upper } \\
\text { 95\% Mean }\end{array}$ & $\begin{array}{c}\text { Lower } \\
95 \% \text { Mean }\end{array}$ & Range \\
\hline Technical Aspects & 7 & 4.19 & 0.61 & 4.43 & 3.94 & 2.57 \\
\hline $\begin{array}{l}\text { Professional- } \\
\text { Patient Interaction }\end{array}$ & 8 & 4.38 & 0.55 & 4.60 & 4.16 & 2.50 \\
\hline $\begin{array}{l}\text { Patient's Feelings } \\
\text { about Consultation }^{\mathrm{a}}\end{array}$ & 8 & 4.33 & 0.55 & 4.54 & 4.11 & 2.25 \\
\hline Overall Satisfaction & 2 & 4.41 & 0.76 & 4.71 & 4.11 & 3.00 \\
\hline $\begin{array}{l}\text { Total Satisfaction } \\
\text { Score of All Items }\end{array}$ & 24 & 4.30 & 0.48 & 4.49 & 4.11 & 1.96 \\
\hline
\end{tabular}

${ }^{a}$ One question was included in two construct measurements giving a total of 25 questions when combining the four constructs 
Table 16: Analysis of Variance of the mean scores from the Telenutrition Satisfaction Survey by age group, education level completed and prior videoconferencing experience $(\mathrm{N}=27)$

\begin{tabular}{lccccc} 
& F-ratio & DF & p-value & R-square & $\begin{array}{c}\text { Adjusted } \\
\text { R-square }\end{array}$ \\
\hline Age (years) & 0.42 & 2 & 0.66 & 0.03 & -0.05 \\
Education Level Completed & 1.43 & 2 & 0.26 & 0.11 & 0.03 \\
Prior videoconferencing experience $^{a}$ & 1.98 & 4 & 0.13 & 0.26 & 0.13 \\
\hline
\end{tabular}

${ }^{a}$ Compares five levels of prior videoconferencing experience: Strongly Agree vs. Agree vs.

Neutral vs. Disagree vs. Strongly Disagree 
Table 17: T-test of the mean scores from the Telenutrition Satisfaction survey by annual household income level, employment status, if unable to fix issue logging into Vidyo portal, and if major disruptions were experienced during the video call $(\mathrm{N}=27)$

\begin{tabular}{|c|c|c|}
\hline & $\mathrm{DF}$ & $\mathrm{p}$-value \\
\hline Annual Household Income Level & 23 & 0.95 \\
\hline Employment Status & 16 & 0.62 \\
\hline Unable to Fix Issue Logging Into Vidyo Portal & 10 & 0.87 \\
\hline Experienced Major Disruptions During Video Call & 23 & 0.96 \\
\hline Prior Videoconferencing Experience ${ }^{\mathrm{a}}$ & 23 & $<0.0001^{*}$ \\
\hline
\end{tabular}

*Significance at $p \leq 0.05$ with DF 23 has $\mathrm{t}$-critical value $=2.069$

${ }^{\text {a}}$ Strongly Agree vs. All Responses less than Strongly Agree 


\section{CHAPTER 6: DISCUSSION}

This study, the first of its kind to evaluate the feasibility of a home telenutrition weightloss program using videoconferencing among obese men in $\mathrm{WV}$, assessed the feasibility of a home telenutrition intervention by analyzing technical difficulties and the results of a satisfaction survey. The overall results of this study provide initial confirmation that this mode of delivery would be feasible and highly acceptable for middle-aged, obese men in WV if implemented in a larger-scale intervention.

\section{Technical Difficulties}

Although technical difficulties logging into the Vidyo portal at the start of the call were experienced by most of the participants, problems were typically resolved in approximately two minutes. If the problem was unable to be fixed, the call was completed via telephone. Finishing the call over telephone was a simple and effective method of overcoming the barriers faced, as also demonstrated in the studies by Luxton et $\mathrm{al}^{12}$ and Robinson et al. ${ }^{58}$

This study demonstrated a high connectivity with establishing the video connection. Only one participant was unable to establish a connection for two of the three scheduled video calls. This finding shows promise for this mode of delivery, especially when compared to the study conducted for home telepsychiatry via videoconferencing by Luxton et al. ${ }^{12}$ in which 31 of 73 video calls (42.5 percent) were not able to connect immediately and the mean amount of time to launch a connection was $5.99(\mathrm{SD}=4.27)$ minutes.

\section{Survey}

\section{Survey Development}

As noted in recent telemedicine literature, validating surveys prior to use is an important step when developing surveys, ${ }^{15,37}$ but one that is often not completed and limits the 
dissemination of the survey results. ${ }^{27,59}$ This study builds off of successful survey validation efforts in previous studies. Bakken et al. ${ }^{37}$ developed, validated, and translated for use in both English and Spanish a satisfaction and usefulness questionnaire following a telehealth diabetes intervention. Furthermore, Yip et al. ${ }^{24}$ also developed a satisfaction survey following a diabetes intervention conducted via videoconferencing in which they assessed its validity and reliability. Contributing to the literature, the survey developed and validated in this study was the first, to our knowledge, to assess the satisfaction of a videoconferencing intervention for nutritional and weight loss counseling.

Survey Results

No statistically significant results were found in comparisons between demographics and mean satisfaction scores, signifying the acceptance of this mode of delivery across all groups. The survey results are also similar to satisfaction survey results in other telemedicine literature. High satisfaction has been found in telepsychiatry, ${ }^{12-14}$ tele-cancer, ${ }^{43,44,60}$ and home health services, ${ }^{48,49}$ among others. ${ }^{16,45,46}$

The highest mean level of satisfaction relating to previous videoconferencing experience was with the participants who strongly agreed with the statement. Therefore, this comparison was explored. Significant differences were found in mean satisfaction scores in participants who felt strongly about previous videoconferencing experience; participants who had more previous experience were more satisfied than those with less experience. This finding is consistent with the results of Bakken et al., ${ }^{37}$ who found significant differences in the satisfaction scores of participants who knew how to use a computer at the start of the study versus those who did not know how. 
However, in reviewing other technology aspects, the amount and type of technical difficulties faced when either logging on or during the course of the call did not appreciably affect participant satisfaction levels. This finding mirrors the findings of a study for home telemental healthcare, in which the participants experienced multiple technical issues but still experienced favorable outcomes, based on level of satisfaction and clinical results. ${ }^{12}$ Furthermore, when comparing the level of prior videoconferencing experience across all five levels ranging from strongly disagree to strongly agree, did not significantly affect mean satisfaction scores among participants. This finding provides evidence that this type of intervention can be implemented even among demographics with minimal experience with the software components. The lack of difference in satisfaction levels between participants with varying levels of technical experience found in our study may be a result of the researchers providing a brief instructional lesson to participants on how to set-up the webcam and providing an instructional sheet in the binder given to participants at baseline on how to download the Vidyo software. These provisions may have increased participant self-efficacy related to the technology, as 25 participants (93.6 percent) rated the video call software as being easy to use. As also demonstrated in recent research by Hoaas et al. ${ }^{61}$ in their study on telerehabilitation for patients with chronic obstructive pulmonary disease, self-efficacy is important because having a high perceived level of self-efficacy when using technology for telehealthcare was a factor that influenced satisfaction. Further research is needed on the effect of providing instructional resources to telenutrition participants on levels of satisfaction and positive outcomes.

While the lack of face-to-face consultations has been identified as a significant drawback to telehealth in previous studies, this study did not find any evidence of a lack of satisfaction among participants due to this factor. Regarding preference for face-to-face consultations, a 
review by Williams et al.0, ${ }^{27}$ found that in 18 studies, the mean (SD) percent satisfied was only 28 (20). This study exhibited much higher levels of patient satisfaction, with 21 participants (77.8 percent) disagreeing with the statement that they would have preferred to meet with the $\mathrm{RDN}$ in person.

Confidentiality was also not deemed to be a drawback in the current sample. Only one participant (3.7 percent) agreed to the statement about having concern about the privacy of his personal medical information. This statement conforms to a study conducted by Rahimpour et al. ${ }^{28}$ on perceptions of a home telecare system, in which the majority of participants within focus groups expressed no concerns as long as the relevant medical professionals received the information.

\section{Limitations and Strengths}

While the methods of this study were rigorous and defined, certain limitations due to sample size and participant demographics provide an opportunity for further research in this area of study. One limitation for this study was a small sample size. Due to the nature of this being a feasibility study, small sample sizes are common. Other telemedicine feasibility studies have been conducted on even smaller sample sizes. For example, in the study by Allen et al. ${ }^{62}$ that studied videoconferencing to the patients' homes for home health care, only three participants and two nurses participated in the survey. Furthermore, in a study by McLaren et al. ${ }^{63}$ that studied videoconferencing linking a hospital to a mental health facility in the community, only three patients were included in the sample.

The current study also has demographic limitations that can be built on in future studies. The sample size for this study had high income and education levels, and all participants were non-Hispanic white. Even if not comparable with other demographics, this sample was 
comparable in race to the general population of $\mathrm{WV}$, with 93.6 percent of West Virginians being identified as white in the 2015 Census data. ${ }^{64}$ Furthermore, the recruitment area through the PCP offices is a more densely populated area of WV. Thus, these results limit the generalizability to other income levels, education levels, races, and locations. Further research is needed to evaluate this generalizability. Furthermore, the required characteristics of participants also limit the generalizability of these results. In an effort to better control the technology conditions for this intervention, the researchers provided the webcam to the participants and required participants to meet an inclusion criteria of having a computer with high-speed internet access at home. This stipulation should be taken into consideration when attempting to expand to lower-income, more rural demographics where computers and high-speed internet access might not be as readily available.

While the limitations of this study provide a good starting point for further research in telenutrition, the strengths of this study can also be replicated to enhance future research in this field. The satisfaction survey developed for this study was validated prior to use and had high overall reliability. Validation is an essential step when developing surveys ${ }^{15,37}$ but is not frequently performed when using new survey instruments, as identified in telemedicine reviews conducted by Demiris et al. ${ }^{15}$ and Williams et al. ${ }^{27}$. The survey also had a 100 percent response rate of those to whom the survey was distributed, because it was administered as part of the intervention. Therefore, the views of all who completed the intervention could be assessed. Furthermore, all participants were instructed to complete the survey themselves, allowing the researchers to more accurately assess the perceptions of the participants themselves and not those of family members or caregivers. The consistency of this survey's results stands in contrast to the ambiguity found in the study by Dick et al., ${ }^{36}$ in which the survey was administered to the family 
and patient with no specific instructions on who should complete it. Survey validation, survey administration as part of the intervention, and independent participant completion of the survey are all characteristics of this study that enhanced the effectiveness of this study's feasibility determination. Future studies in telenutrition would be well served to use these same processes to ensure adequate rigor in evaluating feasibility. 


\section{CHAPTER 7: CONCLUSION}

The rural nature of WV and the few RDNs available in this state together intensify the problem of obesity and its associated comorbidities and increase the need for alternate methods of weight loss. This study demonstrates that telenutrition through videoconferencing to the home can help confront these problems, by providing a new method to reach more middle-aged adults needing nutrition counseling in WV. Despite the technical issues identified, participants demonstrated satisfaction with the research methods used, especially when participants felt high self-efficacy with the technology. Employing untapped methods like telenutrition is especially important in locations like WV where obesity and its consequent comorbidities are in urgent need of rapid improvement. Additional research with a larger sample size is needed, but this knowledge gained will facilitate creating effective future weight loss interventions on a larger scale using videoconferencing. 


\section{REFERENCES}

1. National Institutes of Health (NIH). Overweight and Obesity Statistics. http://www.niddk.nih.gov/health-information/health-statistics/Pages/overweight-obesitystatistics.aspx. Accessed October 26, 2015.

2. West Virginia State Obesity Data, Rates and Trends: The State of Obesity. the STATE of OBESITY. http://stateofobesity.org/states/wv/. Published 2015. Accessed February 5, 2015.

3. Jensen MD, Ryan DH, Apovian CM, et al. 2013 AHA/ACC/TOS Guideline for the Management of Overweight and Obesity in Adults: A Report of the American College of Cardiology/American Heart Association Task Force on Practice Guidelines and The Obesity Society. J Am Coll Cardiol. 2014;63(25, Part B):2985-3023. doi:10.1016/j.jacc.2013.11.004.

4. U.S. Preventive Services Task Force. Final Recommendation Statement: Obesity in Adults: Screening and Management - US Preventive Services Task Force. http://www.uspreventiveservicestaskforce.org/Page/Document/RecommendationStatement Final/obesity-in-adults-screening-and-management. Published June 2012. Accessed March 12, 2015.

5. Kushner RF. Barriers to providing nutrition counseling by physicians: a survey of primary care practitioners. Prev Med. 1995;24(6):546-552. doi:10.1006/pmed.1995.1087.

6. Haughton B, Stang J. Population Risk Factors and Trends in Health Care and Public Policy. J Acad Nutr Diet. 2012;112(3):S35-S46. doi:10.1016/j.jand.2011.12.011.

7. Wantland DJ, Portillo CJ, Holzemer WL, Slaughter R, McGhee EM. The Effectiveness of Web-Based vs. Non-Web-Based Interventions: A Meta-Analysis of Behavioral Change Outcomes. J Med Internet Res. 2004;6(4). doi:10.2196/jmir.6.4.e40.

8. Harvey-Berino J, Pintauro SJ, Gold EC. The Feasibility of Using Internet Support for the Maintenance of Weight Loss. Behav Modif. 2002;26(1):103-116. doi:http://dx.doi.org/10.1177/0145445502026001006.

9. Ahrendt AD, Kattelmann KK, Rector TS, Maddox DA. The effectiveness of telemedicine for weight management in the MOVE! Program. J Rural Health Off J Am Rural Health Assoc Natl Rural Health Care Assoc. 2014;30(1):113-119. doi:10.1111/jrh.12049.

10. Morgan PJ, Lubans DR, Collins CE, Warren JM, Callister R. The SHED-IT Randomized Controlled Trial: Evaluation of an Internet-based Weight-loss Program for Men. Obesity. 2009;17(11):2025-2032. doi:10.1038/oby.2009.85.

11. Morgan PJ, Warren JM, Lubans DR, Collins CE, Callister R. Engaging men in weight loss: Experiences of men who participated in the male only SHED-IT pilot study. Obes Res Clin Pract. 2011;5(3):e239-e248. doi:10.1016/j.orcp.2011.03.002. 
12. Luxton DD, Pruitt LD, O’Brien K, Kramer G. An Evaluation of the Feasibility and Safety of a Home-Based Telemental Health Treatment for Posttraumatic Stress in the U.S. Military. Telemed J E-Health Off J Am Telemed Assoc. June 2015. doi:10.1089/tmj.2014.0235.

13. Callahan EJ, Hilty DM, Nesbitt TS. Patient Satisfaction with Telemedicine Consultation in Primary Care: Comparison of Ratings of Medical and Mental Health Applications. Telemed J. 1998;4(4):363-369. doi:10.1089/tmj.1.1998.4.363.

14. Richardson L, Reid C, Dziurawiec S. "Going the Extra Mile": Satisfaction and Alliance Findings from an Evaluation of Videoconferencing Telepsychology in Rural Western Australia. Aust Psychol. 2015;50(4):252-258. doi:10.1111/ap.12126.

15. Demiris G, Speedie SM, Hicks LL. Assessment of Patients' Acceptance of and Satisfaction with Teledermatology. J Med Syst. 2004;28(6):575-579. doi:10.1023/B:JOMS.0000044959.71456.df.

16. Carlson LE, Lounsberry JJ, Maciejewski O, Wright K, Collacutt V, Taenzer P. Telehealthdelivered group smoking cessation for rural and urban participants: Feasibility and cessation rates. Addict Behav. 2012;37(1):108-114. doi:10.1016/j.addbeh.2011.09.011.

17. Saperstein SL, Atkinson NL, Gold RS. The impact of Internet use for weight loss. Obes Rev. 2007;8(5):459-465. doi:10.1111/j.1467-789X.2007.00374.x.

18. EAL: Telenutrition. Academy of Nutrition and Dietetics Evidence Analysis Library. https://www.andeal.org/topic.cfm?menu=4706\&cat=4907. Accessed April 20, 2015.

19. Weinstein PKM ARNP. A Review of Weight Loss Programs Delivered Via the Internet. $J$ Cardiovasc Nurs. 2006;21(4):251-258.

20. Bowen DJ, Kreuter M, Spring B, et al. How We Design Feasibility Studies. Am J Prev Med. 2009;36(5):452-457. doi:10.1016/j.amepre.2009.02.002.

21. Clarke M, Thiyagarajan CA. A Systematic Review of Technical Evaluation in Telemedicine Systems. Telemed E-Health. 2008;14(2):170-183. doi:10.1089/tmj.2007.0032.

22. Demiris G. Principles of survey development for telemedicine applications. J Telemed Telecare. 2006;12(3):111-115. doi:10.1258/135763306776738549.

23. Institute of Medicine (US) Committee on Evaluating Clinical Applications of Telemedicine. Telemedicine: A Guide to Assessing Telecommunications in Health Care. (Field MJ, ed.). Washington (DC): National Academies Press (US); 1996. http://www.ncbi.nlm.nih.gov/books/NBK45448/. Accessed May 27, 2015.

24. Yip MP, Chang AM, Chan J, MacKenzie AE. Development of the Telemedicine Satisfaction Questionnaire to evaluate patient satisfaction with telemedicine: a preliminary study. J Telemed Telecare. 2003;9(1):46-50. 
25. Barry MJ, Edgman-Levitan S. Shared Decision Making — The Pinnacle of PatientCentered Care. N Engl J Med. 2012;366(9):780-781. doi:10.1056/NEJMp1109283.

26. Donabedian A. The quality of care: How can it be assessed? JAMA. 1988;260(12):17431748. doi:10.1001/jama.1988.03410120089033.

27. Williams TL, May CR, Esmail A. Limitations of Patient Satisfaction Studies in Telehealthcare: A Systematic Review of the Literature. Telemed J E Health. 2001;7(4):293316. doi:10.1089/15305620152814700.

28. Rahimpour M, Lovell NH, Celler BG, McCormick J. Patients' perceptions of a home telecare system. Int J Med Inf. 2008;77(7):486-498. doi:10.1016/j.ijmedinf.2007.10.006.

29. Maheu MM, Whitten P, Allen A. E-Health, Telehealth, and Telemedicine: A Guide to Start-up and Success. San Francisco: Jossey-Bass; 2001. http://www.loc.gov/catdir/description/wiley035/00059093.html. Accessed May 25, 2016.

30. Rollo ME, Hutchesson MJ, Burrows TL, et al. Video Consultations and Virtual Nutrition Care for Weight Management. J Acad Nutr Diet. 2015;115(8):1213-1225. doi:10.1016/j.jand.2015.03.016.

31. Likert R. A Technique for the Measurement of Attitudes. United States - New York: New York University; 1932.

32. Lantz B. Equidistance of Likert-Type Scales and Validation of Inferential Methods Using Experiments and Simulations. Electron J Bus Res Methods. 2013;11(1):16-28.

33. Strachan M, Gros DF, Yuen E, Ruggiero KJ, Foa EB, Acierno R. Home-based telehealth to deliver evidence-based psychotherapy in veterans with PTSD. Contemp Clin Trials. 2012;33(2):402-409. doi:10.1016/j.cct.2011.11.007.

34. Parker Oliver DR, Demiris G, Porock D. The usability of videophones for seniors and hospice providers: a brief report of two studies. Comput Biol Med. 2005;35(9):782-790. doi:10.1016/j.compbiomed.2004.07.001.

35. Davis AM, James RL, Boles RE, Goetz JR, Belmont J, Malone B. The use of TeleMedicine in the treatment of paediatric obesity: feasibility and acceptability. Matern Child Nutr. 2011;7(1):71-79. doi:10.1111/j.1740-8709.2010.00248.x.

36. Dick PT, Filler R, Pavan A. Participant satisfaction and comfort with multidisciplinary pediatric telemedicine consultations. J Pediatr Surg. 1999;34(1):137-142. doi:10.1016/S0022-3468(99)90244-0.

37. Bakken S, Grullon-Figueroa L, Izquierdo R, et al. Development, Validation, and Use of English and Spanish Versions of the Telemedicine Satisfaction and Usefulness Questionnaire. J Am Med Inform Assoc JAMIA. 2006;13(6):660-667. doi:10.1197/jamia.M2146. 
38. Shea S, Starren J, Weinstock RS, et al. Columbia University's Informatics for Diabetes Education and Telemedicine (IDEATel) Project. J Am Med Inform Assoc JAMIA. 2002;9(1):49-62.

39. Flesch R. A new readability yardstick. J Appl Psychol. 1948;32(3):221-233. doi: $10.1037 / \mathrm{h} 0057532$.

40. Timmerberg BD, Wurst J, Patterson J, Spaulding RJ, Belz NE. Feasibility of using videoconferencing to provide diabetes education: a pilot study. $J$ Telemed Telecare. 2009;15(2):95-97. doi:10.1258/jtt.2008.080813.

41. Vadheim LM, McPherson C, Kassner DR, et al. Adapted Diabetes Prevention Program Lifestyle Intervention Can Be Effectively Delivered Through Telehealth. Diabetes Educ. 2010;36(4):651-656. doi:10.1177/0145721710372811.

42. Larsen DL, Attkisson CC, Hargreaves WA, Nguyen TD. Assessment of client/patient satisfaction: development of a general scale. Eval Program Plann. 1979;2(3):197-207.

43. Haozous E, Doorenbos AZ, Demiris G, et al. Role of telehealth/videoconferencing in managing cancer pain in rural American Indian communities. Psychooncology. 2012;21(2):219-223. doi:10.1002/pon.1887.

44. Doorenbos AZ, Eaton LH, Haozous E, Towle C, Revels L, Buchwald D. Satisfaction With Telehealth for Cancer Support Groups in Rural American Indian and Alaska Native Communities. Clin J Oncol Nurs. 2010;14(6):765-770 6p. doi:10.1188/10.CJON.765-770.

45. Friesen CA, Hormuth LJ, Petersen D, Babbitt T. Using Videoconferencing Technology to Provide Breastfeeding Support to Low-Income Women: Connecting Hospital-Based Lactation Consultants with Clients Receiving Care at a Community Health Center. J Hum Lact Off J Int Lact Consult Assoc. August 2015. doi:10.1177/0890334415601088.

46. Parks L, Kim TY. Using Remote Communication Technology in Insulin Pump Training: A Feasibility Study. J Diabetes Sci Technol. September 2015. doi:10.1177/1932296815606917.

47. Saqui O, Chang A, McGonigle S, et al. Telehealth videoconferencing: improving home parenteral nutrition patient care to rural areas of Ontario, Canada. JPEN J Parenter Enteral Nutr. 2007;31(3):234-239.

48. Chae YM, Heon Lee J, Hee Ho S, Ja Kim H, Hong Jun K, Uk Won J. Patient satisfaction with telemedicine in home health services for the elderly. Int J Med Inf. 2001;61(2-3):167173. doi:10.1016/S1386-5056(01)00139-3.

49. Agrell H, Dahlberg S, Jerant AF. Patients' Perceptions Regarding Home Telecare. Telemed J E Health. 2000;6(4):409-415. doi:10.1089/15305620050503889.

50. Harris PA, Taylor R, Thielke R, Payne J, Gonzalez N, Conde JG. Research electronic data capture (REDCap) - A metadata-driven methodology and workflow process for providing 
translational research informatics support. J Biomed Inform. 2009;42(2):377-381. doi:10.1016/j.jbi.2008.08.010.

51. JMP®. Cary, NC: SAS Institute Inc; 1989.

52. Cohen L, Manion L. Research Methods in Education. London: Croom Helm; 1980.

53. Crocker L, Algina J. Introduction to Classical and Modern Test Theory. Belmont, CA: Wadsworth Thomson Learning; 1986.

54. Netemeyer RG, Bearden WO, Sharma S. Scaling Procedures: Issues and Applications. Thousand Oaks, Calif: Sage Publications; 2003. http://www.loc.gov/catdir/toc/fy036/2002014928.html. Accessed May 11, 2016.

55. Cronbach LJ. Essentials of Psychological Testing. 2d ed. New York: Harper; 1960.

56. Nunnally JC, Bernstein IH. Psychometric Theory. 3rd ed. New York: McGraw-Hill; 1994.

57. Kouamé JB. Using Readability Tests to Improve the Accuracy of Evaluation Documents Intended for Low-Literate Participants. J Multidiscip Eval. 2010;6(14):132-139.

58. Robinson MD, Branham AR, Locklear A, Robertson S, Gridley T. Measuring Satisfaction and Usability of FaceTime for Virtual Visits in Patients with Uncontrolled Diabetes. Telemed E-Health. 2015;22(2):138-143. doi:10.1089/tmj.2014.0238.

59. Whitten P, Love B. Patient and Provider Satisfaction with the Use of Telemedicine: Overview and Rationale for Cautious Enthusiasm. J Postgrad Med. 2005;51(4):294-300.

60. Mette LA, Saldívar AMP, Poullard NE, et al. Reaching high-risk underserved individuals for cancer genetic counseling by video-teleconferencing. J Community Support Oncol. 2016;14(4):162-168. doi:10.12788/jcso.0247.

61. Hoaas H, Andreassen HK, Lien LA, Hjalmarsen A, Zanaboni P. Adherence and factors affecting satisfaction in long-term telerehabilitation for patients with chronic obstructive pulmonary disease: a mixed methods study. BMC Med Inform Decis Mak. 2016;16:26. doi:10.1186/s12911-016-0264-9.

62. Allen A, Roman L, Cox R, Cardwell B. Home health visits using a cable television network: user satisfaction. J Telemed Telecare. 1996;2 Suppl 1:92-94.

63. McLaren PM, Blunden J, Lipsedge ML, Summerfield AB. Telepsychiatry in an inner-city community psychiatric service. J Telemed Telecare. 1996;2(1):57-59.

64. West Virginia Quick Facts: United States Census Bureau. //www.census.gov/quickfacts/table/PST045215/00. Accessed June 29, 2016. 